\title{
Are Simulated Megadroughts in the North American Southwest Forced?*
}

\author{
SLOAN COATS \\ Lamont-Doherty Earth Observatory, Columbia University, Palisades, and Department of Earth and Environmental \\ Science, Columbia University, New York, New York \\ JASON E. SMERDON \\ Lamont-Doherty Earth Observatory, Columbia University, Palisades, New York \\ BENJAMIN I. COOK \\ NASA Goddard Institute for Space Studies, New York, and Lamont-Doherty Earth Observatory, Columbia \\ University, Palisades, New York \\ RICHARD SEAGER \\ Lamont-Doherty Earth Observatory, Columbia University, Palisades, New York
}

(Manuscript received 21 January 2014, in final form 24 July 2014)

\begin{abstract}
Multidecadal drought periods in the North American Southwest $\left(25^{\circ}-42.5^{\circ} \mathrm{N}, 125^{\circ}-105^{\circ} \mathrm{W}\right)$, so-called megadroughts, are a prominent feature of the paleoclimate record over the last millennium (LM). Six forced transient simulations of the LM along with corresponding historical (1850-2005) and 500-yr preindustrial control runs from phase 5 of the Coupled Model Intercomparison Project (CMIP5) are analyzed to determine if atmosphere-ocean general circulation models (AOGCMs) are able to simulate droughts that are similar in persistence and severity to the megadroughts in the proxy-derived North American Drought Atlas. Megadroughts are found in each of the AOGCM simulations of the LM, although there are intermodel differences in the number, persistence, and severity of these features. Despite these differences, a common feature of the simulated megadroughts is that they are not forced by changes in the exogenous forcing conditions. Furthermore, only the Community Climate System Model (CCSM), version 4, simulation contains megadroughts that are consistently forced by cooler conditions in the tropical Pacific Ocean. These La Niña-like mean states are not accompanied by changes to the interannual variability of the El Niño-Southern Oscillation system and result from internal multidecadal variability of the tropical Pacific mean state, of which the CCSM has the largest magnitude of the analyzed simulations. Critically, the CCSM is also found to have a realistic teleconnection between the tropical Pacific and North America that is stationary on multidecadal time scales. Generally, models with some combination of a realistic and stationary teleconnection and large multidecadal variability in the tropical Pacific are found to have the highest incidence of megadroughts driven by the tropical Pacific boundary conditions.
\end{abstract}

\section{Introduction}

A stark feature of multidecadal hydroclimate variability in the North American Southwest (NASW; $25^{\circ}-$ $\left.42.5^{\circ} \mathrm{N}, 125^{\circ}-105^{\circ} \mathrm{W}\right)$ is the occurrence of widespread

\footnotetext{
* Lamont-Doherty Earth Observatory Contribution Number 7839.

Corresponding author address: Sloan Coats, Lamont-Doherty Earth Observatory, 61 Route 9W, Palisades, NY 10964.

E-mail: sjc2164@columbia.edu
}

drought conditions lasting decades to centuries [see Cook et al. (2007) for a review]. Understanding the causes of these so-called megadroughts is critical for assessing their likelihood of occurrence in the future and whether their risk probabilities will be influenced by greenhouse gas forcing. The limited $(\sim 150 \mathrm{yr})$ instrumental record necessitates the use of paleoclimate estimates to assess past hydroclimate variability and change on multidecadal time scales. Paleoclimate estimates, however, do not provide a comprehensive view of megadrought dynamics, because they cannot characterize the complete atmosphere-ocean state at the time of 
their occurrence. Atmosphere-ocean general circulation models (AOGCMs) therefore represent complementary means of investigating the atmosphere-ocean dynamics that can give rise to persistent hydroclimate features such as megadroughts. Model-paleo data comparisons that combine insights from these two sources of information are thus vital exercises for evaluation of simulated and real-world low-frequency climate variability (Schmidt et al. 2013).

An important consideration for future hydroclimate change is that it will be determined by both radiatively forced responses and interannual-to-multidecadal internal variability. The ensemble of model simulations completed for the Intergovernmental Panel on Climate Change (IPCC) Fourth and Fifth Assessment Reports (AR4 and AR5) projects widespread drying in the subtropics, including in the NASW, over the coming century (Pachauri and Reisinger 2007; Stocker et al. 2013; Seager et al. 2007a; Seager and Vecchi 2010; Seager et al. 2013). These changes result from increased greenhouse gases driving thermodynamic subtropical drying and responses in atmospheric circulation that expand the subtropical dry zones (Held and Soden 2006; Seager et al. 2010). Concerning variability, tropical Pacific sea surface temperatures (SSTs) have been established as the dominant driver of hydroclimate variability in the NASW on interannual-to-decadal time scales (Schubert et al. 2004a; Seager et al. 2005b; Herweijer et al. 2006; Seager et al. 2007b). A large greenhouse gas-forced change in the tropical Pacific SST pattern consequently has the potential to combine with the model-projected changes described above, with an induced La Niña-like state being a worst-case scenario for future drying in the NASW (e.g., Seager and Vecchi 2010). Nevertheless, there is little agreement on the response of the tropical Pacific to climate change in state-of-the-art AOGCMs [Stocker et al. (2013), sections 1.3.2.4.3, 11.3.3.1, 14.4.1, and 14.4.2]. In these models, both an ocean dynamical change creating a tendency toward a more La Niña-like mean state (Clement et al. 1996) and a weakening of the atmospheric Walker circulation creating a tendency to more El Niñolike conditions (Vecchi et al. 2006) may be operating (DiNezio et al. 2009). While recent observational evidence has indicated a shift toward a more La Niña-like mean state (Karnauskas et al. 2009), this may not be a radiatively forced change, given that models suggest the possibility of large-amplitude internal variability of the tropical Pacific Ocean on centennial time scales (Karnauskas et al. 2012). Furthermore, potential changes to the variability, not the mean state, of El Niño-Southern Oscillation (ENSO) are even less well constrained in the observational and paleoclimate records and in model simulations (Vecchi et al. 2008; Stevenson et al. 2012).
Despite the uncertainties highlighted above, some paleoclimate reconstructions and analyses (Cobb et al. 2003; Herweijer et al. 2007; Mann et al. 2009) and modeling evidence (Graham et al. 2007; Seager et al. 2008; Feng et al. 2008; Oglesby et al. 2011) suggest that observed megadroughts, and more generally past persistent hydroclimate change, were driven by SST boundary conditions in the tropical Pacific and Atlantic. Given these assertions, it is critical to determine if AOGCMs are capable of simulating such dynamics and therefore characterizing the full range of future hydroclimate states in the NASW. Toward such ends, Coats et al. (2013b) used millennium-length simulations from a single AOGCM to show that simulated persistent drought in the NASW can be driven by internal variability of the atmosphere alone, thus occurring independently of the exogenous forcing or SST boundary conditions. If such atmosphere-only processes play an important role in generating multidecadal droughts, it potentially would indicate a limited predictability of the onset, persistence and termination of these features, because prediction and projection efforts are largely dependent on slowly changing SSTs and changes in trace gas concentrations, respectively.

Here we use millennium-length simulations from phase 5 of the Coupled Model Intercomparison Project (CMIP5; Taylor et al. 2012) and phase 3 of the Paleoclimate Modelling Intercomparison Project (PMIP3; Schmidt et al. 2011), and paleoclimate estimates from the North American Drought Atlas (NADA; Cook et al. $2007)$ to investigate megadrought dynamics. Two principal questions will be addressed: 1) Do fully coupled AOGCMs simulate persistent multidecadal droughts similar to those in the paleoclimate record? 2) Are these events driven by variations in exogenous forcing conditions and/or oceanic boundary conditions [for instance, the ENSO-NASW teleconnection (Schubert et al. 2004a,b; Seager et al. 2005a, 2008; Herweijer et al. 2006)]? Answers to these questions are critical for improving our understanding of multidecadal drought dynamics and in determining whether AOGCMs are capable of providing robust estimates for the range of future hydroclimate states in the NASW and, hence, realistic projections of regional hydroclimate change and variability on decadal-to-centennial time scales.

\section{Data and methods}

\section{a. Model and proxy inputs}

All model output is from the CMIP5/PMIP3 archive (models and expanded model names are provided in Table 1). We employ six last-millennium (LM) transient simulations forced with reconstructed time-varying 
TABLE 1. Model information for the analyzed CMIP5 simulations.

\begin{tabular}{|c|c|c|}
\hline Modeling center & Model & Expanded model name \\
\hline $\begin{array}{l}\text { Beijing Climate Center (BCC), China Meteorological } \\
\text { Administration }\end{array}$ & BCC_CSM1.1 & $\begin{array}{l}\text { BCC, Climate System Model, } \\
\text { version } 1.1\end{array}$ \\
\hline National Center for Atmospheric Research (NCAR) & CCSM4 & $\begin{array}{l}\text { Community Climate System Model, } \\
\text { version } 4\end{array}$ \\
\hline $\begin{array}{l}\text { National Aeronautics and Space Administration (NASA) } \\
\text { Goddard Institute for Space Studies (GISS) }\end{array}$ & GISS-E2-R & $\begin{array}{l}\text { GISS Model E2, coupled with the } \\
\text { Russell ocean model }\end{array}$ \\
\hline L'Institut Pierre-Simon Laplace (IPSL) & IPSL-CM5A-LR & $\begin{array}{l}\text { IPSL Coupled Model, version 5A, } \\
\text { low resolution }\end{array}$ \\
\hline $\begin{array}{l}\text { Japan Agency for Marine-Earth Science and Technology, } \\
\text { Atmosphere and Ocean Research Institute (The University } \\
\text { of Tokyo), and National Institute for Environmental Studies }\end{array}$ & MIROC-ESM & $\begin{array}{l}\text { Model for Interdisciplinary Research } \\
\text { on Climate (MIROC), Earth } \\
\text { System Model }\end{array}$ \\
\hline Max Planck Institute (MPI) for Meteorology & $\begin{array}{l}\text { MPI-ESM-LR, } \\
\text { MPI-ESM-P }\end{array}$ & $\begin{array}{l}\text { MPI Earth System Model, low resolution } \\
\text { and paleoclimate versions }\end{array}$ \\
\hline
\end{tabular}

exogenous forcings from 850 to $1850 \mathrm{CE}$ (Schmidt et al. 2011). These simulations have been appended to the first ensemble member of the CMIP5 historical runs that span the period 1850-2005 CE to produce a model record from 850 to $2005 \mathrm{CE}$. Although these simulations are not continuous, both the historical and LM simulations have the same model configuration and resolution. Consequently, if the simulations have no drift, the discontinuity at 1850 should fall within the range of simulated climate variability. A large temperature drift in the MIROC LM simulation (Sueyoshi et al. 2013) likely violates this assumption, while a drift in the early centuries of the GISS LM simulation (Bothe et al. 2013) is likely to have less of an impact. While model drift undoubtedly impacts the hydroclimate variables assessed in this study, the effects are presumed to be moderate given the absence of drift in precipitation (Sen Gupta et al. 2013). The 500-yr control simulations with constant preindustrial forcing conditions (also from CMIP5) were additionally analyzed to aid in the interpretation of the LM model results. All model output has been regridded to a common $2.5^{\circ} \times 2.5^{\circ}$ latitude-longitude grid (this represents a coarsening of the model resolution for four out of the six models) to allow direct comparison to the paleo drought product described below.

The Palmer drought severity index (PDSI) is calculated for each model simulation. PDSI is an offline estimate of soil moisture balance and has been established as a robust estimator of soil moisture variability that compares well to other soil moisture metrics [e.g., the standardized precipitation evapotranspiration index (SPEI; Vicente-Serrano et al. 2010; Cook et al. 2014)] and model soil moisture (Cook et al. 2014; Smerdon et al. 2014, manuscript submitted to J. Climate). PDSI is calculated from supply via precipitation and losses due to evapotranspiration (ET). PDSI ET is estimated by means of scaling potential evapotranspiration (PET) using a fixed beta function that is meant to represent vegetative controls on transpiration (e.g., stomata closure to reduce moisture stress). PET is often estimated using surface temperature via the Thornthwaite method (Thornthwaite 1948). Because Thornthwaite-estimated PET is essentially a rescaling of surface temperature, it overestimates the PET influence on PDSI when temperatures far exceed the climatology of the PDSI standardization interval (see Milly and Dunne 2011; Sheffield et al. 2012; Coats et al. 2013b; Dai 2013; Smerdon et al. 2014, manuscript submitted to $\mathrm{J}$. Climate). For a detailed treatment of the differences in PET estimates based on temperature, net radiation, and other physical variables, see the supplementary material of Sheffield et al. (2012). In this case we use model surface net radiation (RNET) to estimate PET. To do so, simulated monthly RNET ( $\mathrm{W} \mathrm{m}^{-2}$ ) was set equal to PET (mm day $\left.{ }^{-1}\right)$. This is equivalent to assuming that RNET is exactly balanced by latent heat through ET (with sensible heat flux equal to zero). The ideal method for computing PDSI is to estimate PET via the PenmanMonteith (PM) method, which includes the effect of the vapor pressure deficit along with the impact of RNET [a more detailed treatment of PM PDSI can be found in Sheffield et al. (2012); Cook et al. (2014); and Smerdon et al. (2014, manuscript submitted to J. Climate)]. Unfortunately, the necessary model fields to compute PM PET were only available for three out of the six analyzed LM simulations. A comparison of the RNET and PM PDSI for these three simulations is included in section 3a. Unless otherwise specified, PDSI will be used throughout the remainder of this study to specifically designate PDSI calculated using the RNET formulation.

For the analyses performed herein, model PDSI is derived on an even $2.5^{\circ} \times 2.5^{\circ}$ grid. At each grid point, PDSI was calculated and then standardized against an instrumental normalization period (1931-90 CE) for the forced simulations and the full 500-yr period for the control simulations. The instrumental normalization 
period is the same time interval used by the National Oceanic and Atmospheric Administration for normalization of their PDSI calculations (Cook et al. 2014), which were subsequently used as the target PDSI for the paleoclimate reconstructions described below. Soil moisture capacity was specified as 25.4 and $127 \mathrm{~mm}$ in the top and bottom layers of the PDSI calculation, respectively. The PDSI was averaged over June-August (JJA) to produce a single average for each year; hereinafter, any mention of PDSI will be with regard to the JJA average values. PDSI with an absolute value over 10 was removed by replacement with the average PDSI of the eight neighboring grid points at that time step as a means of removing unrealistically anomalous PDSI values. This method for removing data errors is consistent with that used by Van der Schrier et al. (2011) in the calculation of their observed PDSI dataset.

Reconstructed PDSI data are from the tree ringderived NADA version 2a, the full details of which can be found in Cook et al. (2007). The data are reconstructed on a $2.5^{\circ} \times 2.5^{\circ}$ latitude-longitude grid of JJA average PDSI values for the United States, as well as northwestern Canada and northern Mexico (286 grid points in total).

\section{b. The NASW region}

The NASW region $\left(25^{\circ}-42.5^{\circ} \mathrm{N}, 125^{\circ}-105^{\circ} \mathrm{W}\right)$ was chosen for three reasons: 1) to match the choice of region in our previous work (Coats et al. 2013b); 2) the NASW is the region of North America that is most dominantly connected to the tropical Pacific, and testing the relationship between the tropical Pacific and megadroughts is a central goal of this paper; and $3)$ megadroughts in the NADA are large in scale and consistently dry over the entire NASW. Importantly, the NASW encompasses two distinct hydroclimate regimes, with winter precipitation modulated by midlatitude eddies and summer precipitation controlled by North American monsoon (NAM) dynamics. To the extent possible, model biases in the simulation of these hydroclimate regimes will be related to the PDSI calculation and our results in section $3 \mathrm{~b}$.

\section{c. Drought identification metric}

A hydroclimate time series was calculated for both the NADA and model simulations by spatially averaging the PDSI over the NASW region. The resulting time series were used to identify droughts, with a drought commencing after two consecutive years of negative PDSI and continuing until two consecutive years of positive PDSI [2S2E; see Coats et al. (2013b) for further details]. This metric requires that the hydroclimate time series have a mean of zero over the full record. As a consequence, the mean PDSI at each grid point over the full record was removed before spatially averaging. This is necessary because PDSI is susceptible to mean shifts as a result of the short normalization interval (e.g., if the normalization interval is relatively wet or dry).

As in Coats et al. (2013b), the identified droughts in the NASW mean PDSI time series were ordered using a cumulative drought severity rank. To do so, PDSI values were summed from the first to the last year of each identified drought, with the first ranked drought then having the largest negative value of this sum. For the analyses in this paper, focus will be restricted to the five highest-ranking (or most severe) droughts in each simulation and in the paleo-proxy record. The cumulative drought severity ranking was chosen over a purely length-based ranking in order to incorporate both the persistence and severity of each drought. The $2 \mathrm{~S} 2 \mathrm{E}$ and cumulative drought severity method will hereinafter be referred to as the drought identification metric.

\section{d. Dynamical mode definitions}

For each control model simulation the following dynamical modes will be calculated, with seasonality determined by the peak season of the impact of that mode of variability on the NASW (see also Table 2):

1) JJA Atlantic multidecadal oscillation [AMO; extratropical North Atlantic SST anomaly following Enfield et al. (2001)];

2) December-February (DJF) Pacific decadal oscillation [PDO; leading empirical orthogonal function (EOF) of monthly SST anomalies poleward of $20^{\circ} \mathrm{N}$ following Zhang et al. (1997)];

3) DJF central equatorial Indian Ocean [CEI; SST anomaly over $15^{\circ} \mathrm{N}-0^{\circ}, 50^{\circ}-80^{\circ} \mathrm{E}$, following Goddard and Graham (1999)];

4) JJA tropical Atlantic Ocean (annually averaged anomaly of Atlantic SSTs from the equator to $20^{\circ} \mathrm{N}$ ); and

5) DJF ENSO-tropical Pacific gradient (TPGR), following Karnauskas et al. (2009), Niño-1 + 2 (average SST anomaly over $\left.10^{\circ} \mathrm{S}-0^{\circ}, 90^{\circ}-80^{\circ} \mathrm{W}\right)$, Niño-3 (average SST anomaly over $5^{\circ} \mathrm{S}-5^{\circ} \mathrm{N}, 150^{\circ}-90^{\circ} \mathrm{W}$ ), Niño-3.4 (average SST anomaly over $5^{\circ} \mathrm{S}-5^{\circ} \mathrm{N}, 170^{\circ}-$ $120^{\circ} \mathrm{W}$ ), and Niño-4 (average SST anomaly over $\left.5^{\circ} \mathrm{S}-5^{\circ} \mathrm{N}, 150^{\circ} \mathrm{W}-160^{\circ} \mathrm{E}\right)$.

The tropical Atlantic SST index was chosen based on prior work that shows it to be the equatorial component, as opposed to the extratropical component, of the AMO that influences North American hydroclimate (e.g., Sutton and Hodson 2005; Kushnir et al. 2010). However, as shown in Ting et al. (2011), models tend to have weak expressions of the AMO in the tropical region. 
TABLE 2. Modes of atmosphere-ocean and exogenous variability and the impact of these on the NASW. The "index" column notes the reference or method for calculating the index for the mode listed in the first column. The "phase" is that which drives drying in the NASW, as concluded by the reference in the "NASW impact" column. The "index sign" is the sign of the index during that phase.

\begin{tabular}{|c|c|c|c|c|}
\hline & Index & Phase & Index sign & NASW impact \\
\hline $\begin{array}{l}\text { ENSO-Tropical } \\
\text { Pacific }\end{array}$ & TPGR (Karnauskas et al. 2009) & Cool & Positive & Sarachik and Cane (2010) \\
\hline $\begin{array}{l}\text { ENSO-Tropical } \\
\text { Pacific }\end{array}$ & $\begin{array}{l}\text { Niño-1 }+2 \text {, Niño-3, Niño-3.4, } \\
\text { and Niño-4 }\end{array}$ & Cool & Negative & Sarachik and Cane (2010) \\
\hline AMO & Enfield et al. (2001) & Warm & Positive & McCabe et al. (2004) \\
\hline PDO & Zhang et al. (1997) & Cool & Negative & McCabe et al. (2004) \\
\hline $\begin{array}{r}\text { Equatorial } \\
\text { Atlantic }\end{array}$ & $\begin{array}{l}\text { Annually averaged SST anomaly } \\
\text { from equator to } 20^{\circ} \mathrm{N} \text { in Atlantic }\end{array}$ & Warm & Positive & Oglesby et al. (2011) \\
\hline $\begin{array}{l}\text { Global } \\
\text { temperature }\end{array}$ & $\begin{array}{l}\text { Annual and globally averaged } \\
\text { temperature }\end{array}$ & Warm & Positive & $\begin{array}{l}\text { Held and Soden (2006); } \\
\quad \text { Seager and Vecchi (2010) }\end{array}$ \\
\hline Indian Ocean & CEI (Goddard and Graham 1999) & Cool & Negative & Hoerling and Kumar (2003) \\
\hline
\end{tabular}

The use of five different indices of tropical Pacific variability, with centers of action in different regions of the tropical Pacific basin, guards against the possibility that a single ENSO index may not adequately capture ENSO variability across all of the models. The TPGR index is a measure of the difference between SSTs averaged over $5^{\circ} \mathrm{S}-5^{\circ} \mathrm{N}, 150^{\circ} \mathrm{E}-160^{\circ} \mathrm{W}$ and $5^{\circ} \mathrm{S}-5^{\circ} \mathrm{N}, 130^{\circ}-80^{\circ} \mathrm{W}$, and it reflects the zonal temperature gradient between the western and eastern ends of the equatorial tropical Pacific basin. The Niño-1 + 2, Niño-3, Niño-3.4, and Niño-4 indices, by contrast, reflect the average SST anomaly over a single spatial region in the tropical Pacific.

Our understanding of the above-listed modes of variability and their "drying" (driving anomalously dry conditions) or "wetting" (driving anomalously wet conditions) impact on the NASW is based on the literature in the "NASW impact" section of Table 2. In each case, the (cool or warm) phase of the mode that drives drying in the NASW will be listed along with the corresponding (positive or negative) orientation of the associated index. These studies variously employ the paleoclimate record, observations, modeling results, physical theory, or some combination thereof to define the NASW hydroclimate state during each phase of the various indices (e.g., a La Niña-like or positive state in the TPGR index is associated with drying in the NASW).

\section{Methodology and assessment of model climatologies and biases}

\section{a. Methodological validation}

As stated above, RNET PDSI is used instead of PM PDSI for the following three reasons: 1) the required input fields for PM PDSI are only available for three of the six employed models; 2) there is general agreement in drought timing and severity between the PM and RNET PDSI when using the drought identification metric; and 3) there is close agreement between the RNET and PM PDSI on both interannual and decadal time scales. We demonstrate support for justifications two and three in the remainder of this section.

The right panels in Fig. 1 show a comparison of the PM and RNET PDSI for the CCSM, GISS model, and MIROC simulation. There is good agreement between the NASW average PM and RNET PDSI time series, with $R^{2}$ values on interannual and decadal (not shown) time scales of approximately 0.99 .

Figure 1 also identifies for each model the five most severe droughts in the PM and RNET PDSI time series using the drought identification metric. For 11 of 15 cases, the same drought was identified in the two PDSI time series, and each of the five most severe droughts identified in the RNET PDSI are also droughts in the PM PDSI. These results indicate that any differences in drought identification between PM and RNET PDSI result from a reordering of the droughts as ranked by cumulative drought severity.

\section{b. Model biases and PDSI}

The PDSI calculation used herein incorporates model precipitation and net radiation to estimate soil moisture balance. Observations of surface energy balance are difficult to come by (e.g., Wild et al. 2013), and because PDSI is largely dominated by precipitation variability (e.g., Van der Schrier et al. 2011), simulated surface net radiation biases will not be analyzed. Biases pertaining to model simulation of the spatial and temporal distribution of precipitation, however, are well documented [e.g., Stocker et al. (2013), sections 9.5.2.4 and 9.6.1.1]. The NASW encompasses a significant portion of the North American monsoon region (Gochis et al. 2009) and thus has both winter and summer precipitation driven by largely independent atmosphere-ocean dynamics (winter precipitation is related to transient 
CCSM
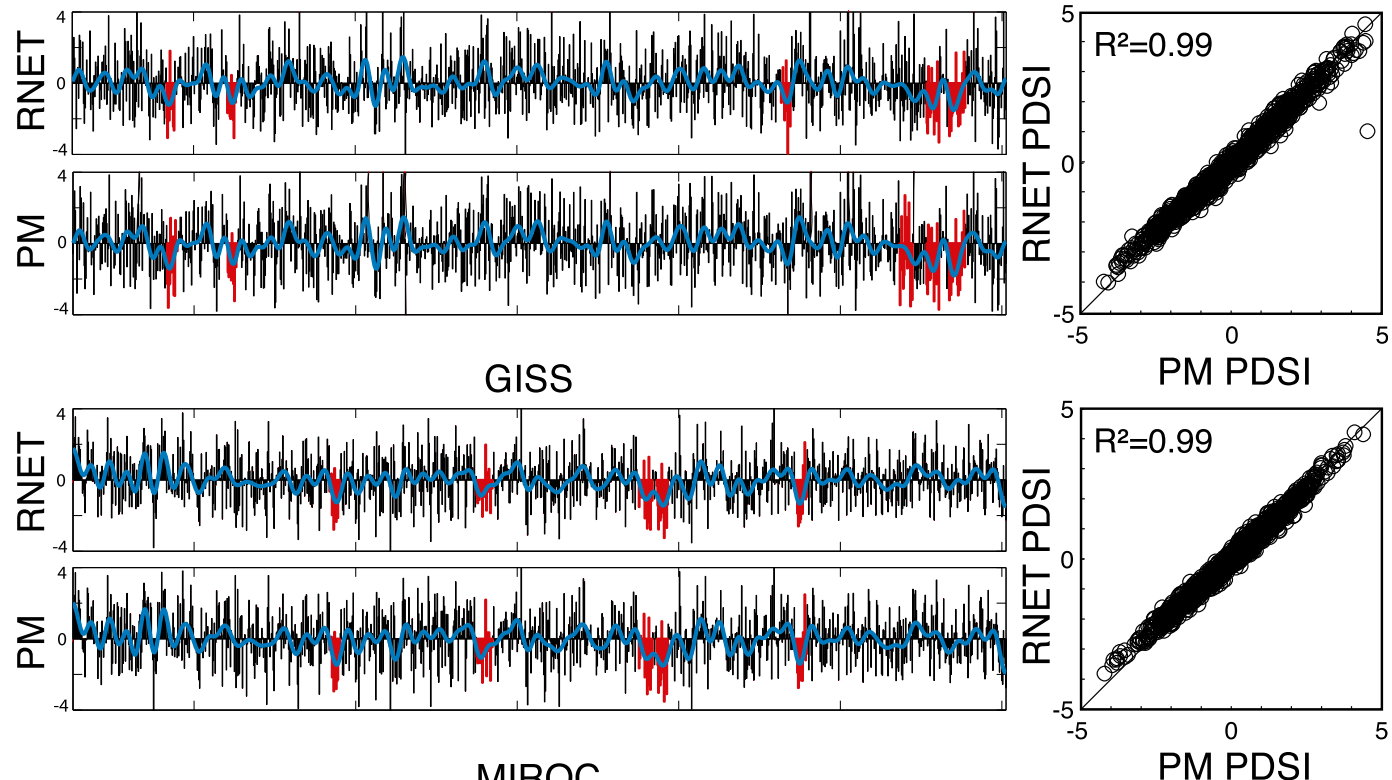

MIROC
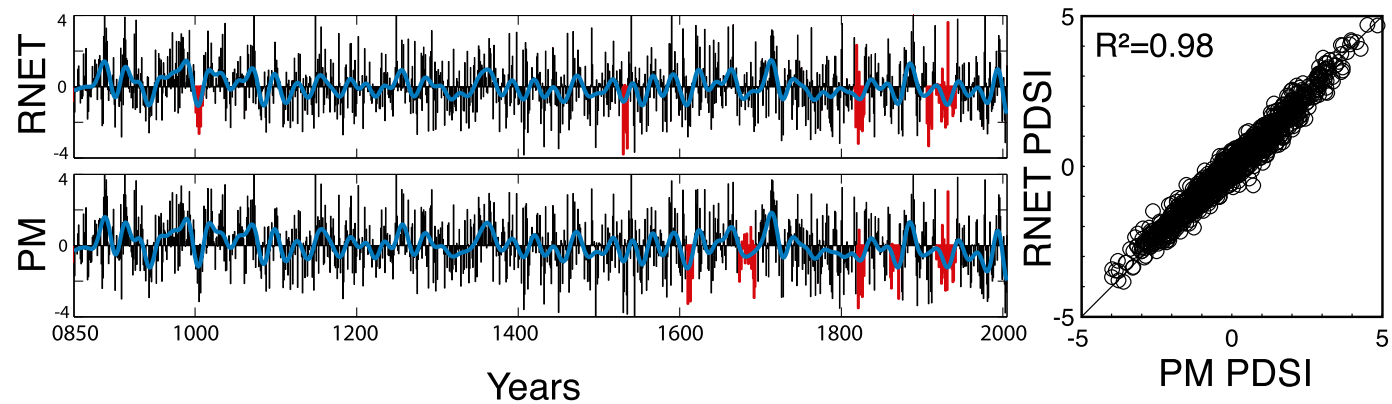

FIG. 1. (left) RNET and PM PDSI time series for the period 850-2005 CE averaged over the NASW region for the three simulations that have provided the necessary output fields. Annual anomalies (black lines) are shown, along with smoothed versions using a 20-yr low-pass filter (blue lines). The red highlighted periods in the annual time series are the five largest droughts in each model, as determined by the $2 \mathrm{~S} 2 \mathrm{E}$ drought definition and the cumulative drought severity ranking. (right) The NASW average PM PDSI is plotted against RNET PDSI over the same period used for the time series plots and indicates the two calculated indices to be very similar (one-to-one lines are shown as black solid lines in each plot).

midlatitude eddies, while summer precipitation is controlled by the monsoon dynamics). Here we compare the model precipitation to observed data from the Global Precipitation Climatology Centre (GPCC) for the period 1951-2010, for which there are 26 precipitation stations over the NASW (Becker et al. 2013).

The spatial distribution of precipitation for the winter [November-April (NDJFMA)] and summer [MayOctober (MJJASO)] half years is plotted in Fig. 2. Models reproduce many elements of the observed precipitation distribution, the main exceptions being a tendency to simulate precipitation that is not limited spatially to the western coastal region in winter and to the southeastern portion of the NASW in summer, and difficulty simulating summer precipitation that peaks sharply in midsummer. In each case, these model biases can be related to the relatively coarse inherent model resolution that prevents a realistic simulation of orographic features. The erroneous spread of winter precipitation away from the coast, for instance, is largely due to the models not resolving the western North American coastal mountain ranges that effectively remove moisture from incoming westerlies and storm systems (e.g., Sheffield et al. 2013). Additionally, realistic simulation of the North American monsoon is predominantly found in the CMIP5 models with high spatial resolution (Langford et al. 2014).

Of the models analyzed herein, the MPI model simulates the observed spatial and temporal precipitation characteristics with the greatest fidelity. MIROC exhibits 

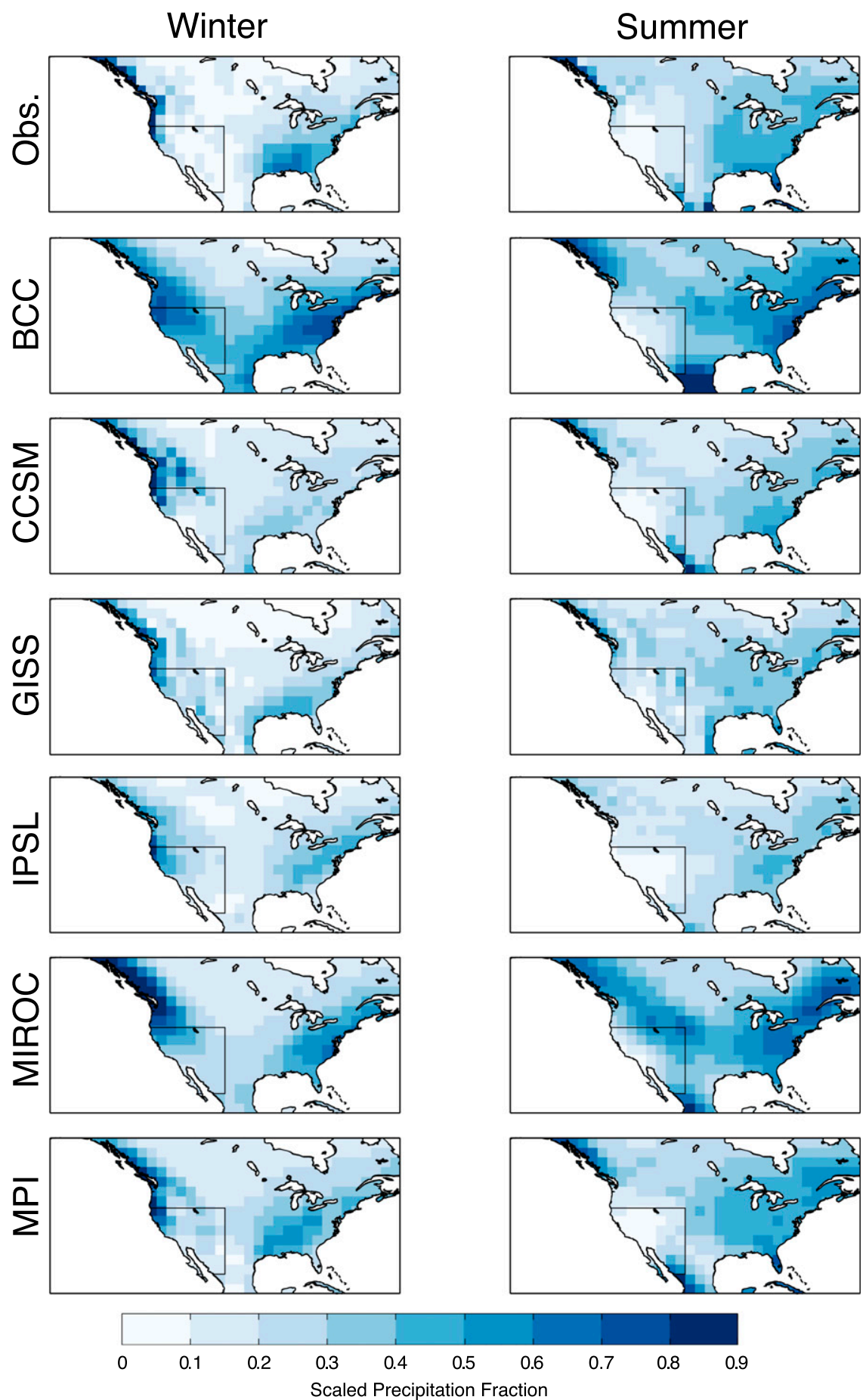

FIG. 2. Fraction of precipitation at each grid point for the mean winter (NDJFMA) and summer (MJJASO) half years. Each value is scaled by the ratio of the yearly integrated precipitation at that grid point to the largest yearly integrated precipitation in the NASW to provide a sense for the contribution of each grid point's half-year integrated precipitation to the yearly integrated NASW spatial average precipitation. 
a large summer precipitation bias over the northeastern half of the NASW and, along with BCC, simulates winter precipitation that is not localized along the western coastal region as observed. In contrast, CCSM, GISS, and IPSL all simulate a reasonable spatial distribution of winter precipitation, although the amount of precipitation is too large in all of the model simulations. For summer precipitation, neither GISS nor IPSL simulates summer precipitation in the southeastern portion of the NASW. The CCSM, on the other hand, simulates relatively realistic summer precipitation, but it does not peak sharply in midsummer as observed. The BCC model has a summer precipitation maximum in the NASW that is approximately correct in its spatial distribution, but the feature extends too far eastward outside of the NASW box, and it likewise does not peak in midsummer. Additionally, all of the models overestimate the magnitude and variability of NASW precipitation (not shown).

It is important to characterize how these biases may impact the results presented herein. JJA PDSI reflects hydroclimate conditions for the past 12-18 months because of persistence built into the PDSI calculation, and as a consequence, precipitation biases in both seasons will impact PDSI. Nevertheless, tree ring-reconstructed PDSI has been shown to predominately reflect winter season precipitation variability over the NASW region (St. George et al. 2010; Griffin et al. 2013), a characteristic that is likely shared by the models. If this is the case, the impact of underestimating summer precipitation on comparisons between model and reconstructed PDSI may be minimal. Nevertheless, the model-paleo data comparison herein will be limited to determining if models can simulate drought features with similar persistence and severity to the megadroughts in the reconstruction. The limitations of the paleoclimate record, however, make it unclear if the models are simulating these features for the right reasons (e.g., do reconstructed megadroughts result from winter, summer, or dual-season precipitation shortages?).

\section{Modeled and proxy-reconstructed megadrought dynamics}

\section{a. Model-paleo multidecadal drought comparisons}

The time series of PDSI averaged over the NASW box for the LM historical simulations and the NADA are shown in Fig. 3, along with the timing and duration of the five highest-ranking droughts (as ranked by the drought identification metric). There are droughts in the model simulations that are characteristic of the severity and persistence seen in the proxy estimates (Fig. 4). In particular, every model but MIROC simulates at least five 15-yr droughts with a cumulative drought severity value between -10 and -17 . This is consistent with the NADA, which has eight $15-\mathrm{yr}$ droughts, though with a slightly larger cumulative drought severity of -18 . Furthermore, all models except MPI simulate at least one 20-yr drought, as in the NADA. This suggests that models, in general, are able to simulate persistent drought and that these droughts have similar severity, albeit slightly reduced, relative to the megadroughts in the proxy record.

The ability of models to simulate a realistic frequency of persistent drought occurrence is perhaps surprising for three reasons: 1) the CMIP5 models, including those analyzed herein, have been shown to exhibit less hydroclimate persistence than the observed or paleoclimate record (Ault et al. 2012, 2013); 2) the models analyzed herein do not have dynamical vegetation, which has been shown to impact simulated climate variability (e.g., Sun and Wang 2014); and 3) the individual soil and land surface components within the model ensemble span a range of complexity, which will impact the ability of models to simulate realistic low-frequency variability in terrestrial water storage. None of these issues appears to greatly impact the ability of models to simulate persistent drought that is characteristic of the paleoclimate reconstruction. The apparent impact of point three, however, may be partially mitigated by the use of PDSI, an offline soil moisture estimate, as the analyzed hydroclimate metric.

Although the models are capable of simulating megadroughts in the NASW, these features are not coincident in time across model simulations, despite the fact that the models were run with similar forcing series [see Schmidt et al. (2011) and Table 3, which lists the forcings employed in each simulation]. Furthermore, there are no statistically significant interannual correlations between any of the NASW hydroclimate time series and weak correlations for filtered 10-yr low-pass time series (separated using a 10-point Butterworth filter). Nevertheless, the CMIP5 models have different climate sensitivities and, in particular, different parameterizations of land surface and aerosol processes that may drive compensating feedbacks and mask the model response to external forcing. With this caveat, the results presented above suggest that simulated megadroughts, and more generally hydroclimate in the NASW, are predominantly driven by internal variability of the modeled atmosphere-ocean system. A comparison between the number of 10-, 15-, and 20-yr drought features in 500-yr control simulations and the range in these values for sliding 500-yr segments in the forced simulations, however, indicates that exogenous forcing may impact simulated hydroclimate variability in the NASW 


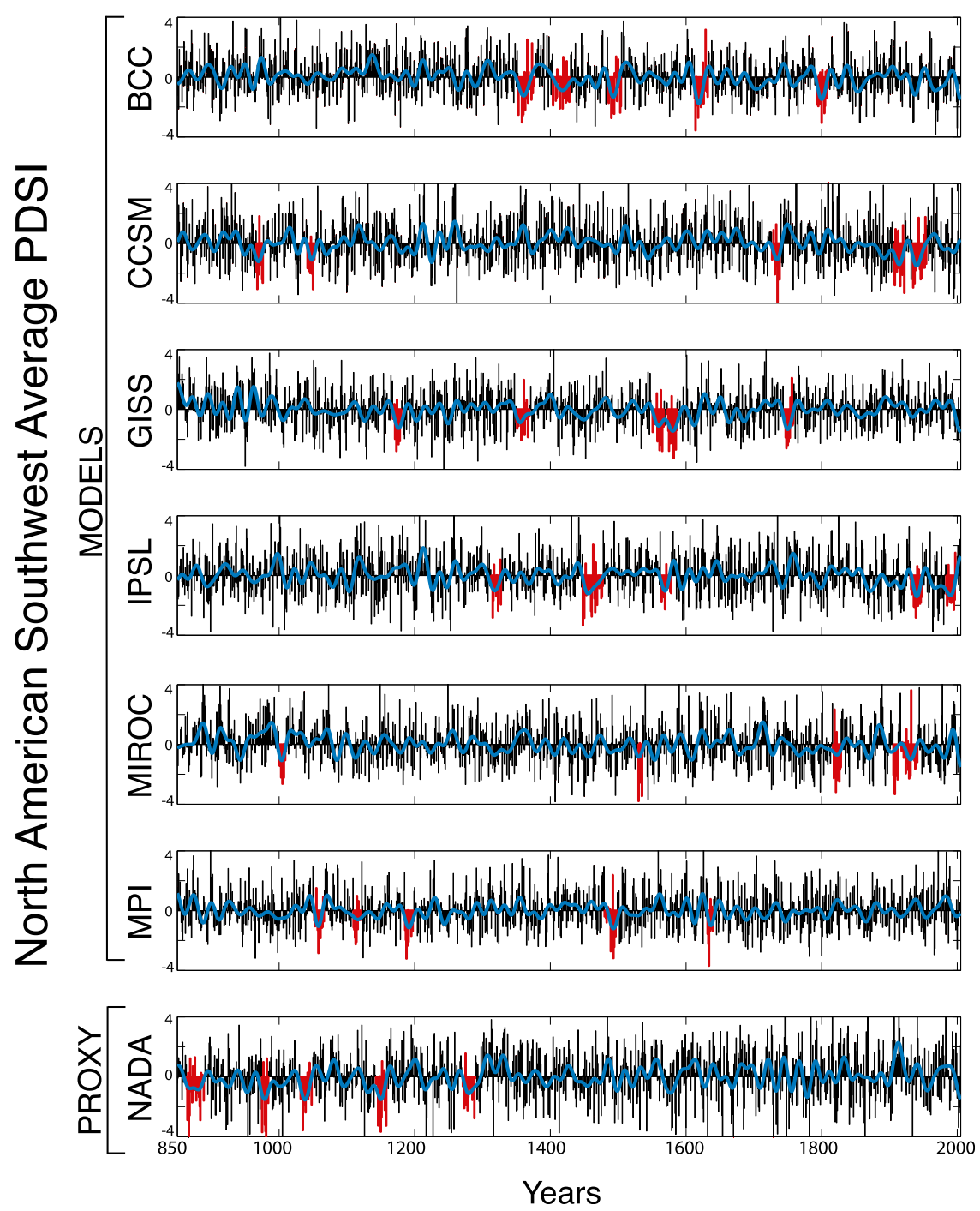

FIG. 3. Proxy-reconstructed and simulated PDSI for the period 850-2005 CE averaged over the NASW region. Annual anomalies (black lines) are shown, along with smoothed versions using a 20-yr low-pass filter (blue lines). The red highlighted periods in the annual time series are the five largest droughts, as determined by the $2 \mathrm{~S} 2 \mathrm{E}$ drought definition and the cumulative drought severity ranking.

in different ways for different models (Fig. 5). In particular, the MIROC and MPI control simulations have more persistent droughts than the corresponding forced simulations. This was also found for the ECHAM4 and the global Hamburg Ocean Primitive Equation (ECHO-G) model (Coats et al. 2013b) and suggests that the forcing in some models may act to interrupt persistent hydroclimate features via, for instance, volcanic driven changes to circulation and precipitation. Nevertheless, the analyzed models are split between showing greater or fewer numbers of 10-, 15-, and 20-yr droughts in the forced versus the control simulations (BCC tends to have more persistent droughts in the forced simulation, while the range overlaps for CCSM4, GISS-E2-R, and MPIESM). Furthermore, 10 of the 18 possible combinations of model and drought length yield control values that fall within the range estimated from the forced simulations. There is thus no compelling evidence in the analyzed collection of models for an important and consistent role played by exogenous forcing in driving simulated hydroclimate variability on decadal time scales. To simplify dynamical interpretations, the diagnosis of megadrought dynamical causes will thus be completed using the 500-yr control simulations from each of these models (all analyses hereafter, unless noted, are with these control simulations). 


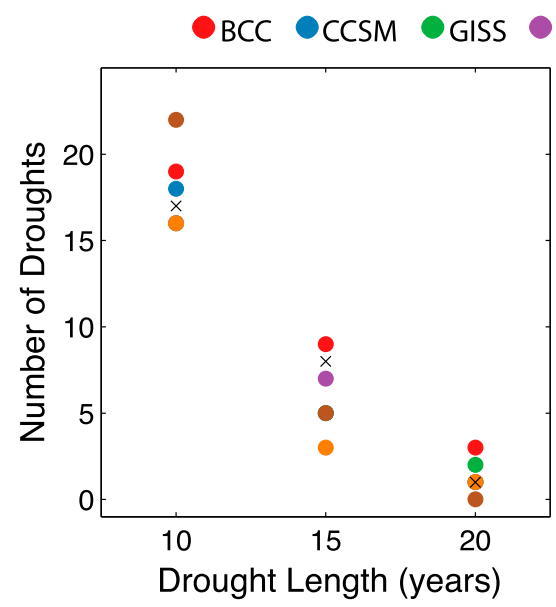

MIROC OMPI XRecon

FIG. 4. (left) The number of 10-, 15-, and 20-yr droughts and (right) the average cumulative drought severity for droughts of each length for the full length of the forced simulations, as compared to drought length and severity observed in the NADA reconstruction.

\section{b. Diagnosis of megadrought dynamical causes}

While the NASW average PDSI indicates that models are capable of simulating megadroughts, the inherent persistence and multiple inputs to PDSI justify the need to determine if changes to precipitation or the surface energy balance, and in what season, are driving these features. An analysis of the surface energy balance and precipitation fields during megadroughts in the winter and summer seasons indicates that megadroughts are consistently associated with anomalously high winter precipitation over the Northwest and low winter precipitation over the Southwest coastal regions of North America in all of the simulations (Fig. 6). This spatial pattern is reminiscent of the precipitation anomaly during La Niña winter and spring [e.g., Seager et al. (2014), their Fig. 1], but recent work has suggested that atmospheric-only dynamics can produce this feature (Coats et al. 2013b).
To assess how the PMIP3 models generate megadroughts, Fig. 7 investigates the association of model megadroughts with various climate modes. If the magnitude of the circle in Fig. $7 \mathrm{a}$ is at the $100 \%$ drying level, then $100 \%$ of the megadrought years are coincident in time with index values of a given dynamic mode that are typically associated with dry conditions in the NASW (based on the references listed in Table 2). The values for each individual megadrought are also plotted in Fig. 7b. To test the statistical significance of these associations, we use a bootstrapping method (Schreiber and Schmitz 2000) to produce 5000 surrogate indices that exactly preserve the distribution of each dynamic-mode index while largely preserving the spectral characteristics (there will be a slight whitening of the surrogate spectrum). The magnitude of the artificial indices was recorded for each megadrought year identified in the NASW PDSI time series. Significance at the $95 \%$ level is achieved if the drying or wetting mode of the true

TABLE 3. Forcing series used to run the last-millennium simulations (from http://pmip3.lsce.ipsl.fr). The Joos table is available online at https://wiki.lsce.ipsl.fr/pmip3/lib/exe/fetch.php/pmip3:design:lm:ghg_lawdome_giss_merge_c5mip_24jul09.1-2000.txt.

\begin{tabular}{|c|c|c|c|c|}
\hline & Orbital & GHG & Volcanic & Solar \\
\hline BCC_CSM1.1 & PMIP3 table & Joos table & Gao et al. (2008) & $\begin{array}{l}\text { Vieira and Solanki (2010) and } \\
\text { Wang et al. (2005) back }\end{array}$ \\
\hline CCSM4 & Internally calculated & Joos table & Gao et al. (2008) & Vieira and Solanki (2010) \\
\hline GISS-E2-R & Internally calculated & Joos table & Crowley et al. (2008) & $\begin{array}{l}\text { Vieira and Solanki (2010) and } \\
\text { Wang et al. (2005) back }\end{array}$ \\
\hline IPSL-CM5A-LR & Internally calculated & Joos table & Gao et al. (2008) & $\begin{array}{l}\text { Vieira and Solanki (2010) and } \\
\text { Wang et al. (2005) back }\end{array}$ \\
\hline MPI-ESM & PMIP3 table & Joos table & Gao et al. (2008) & $\begin{array}{l}\text { Vieira and Solanki (2010) and } \\
\text { Wang et al. (2005) back }\end{array}$ \\
\hline MIROC-ESM & PMIP3 table & $\begin{array}{l}\text { Joos table; } \mathrm{CO}_{2} \text { is } \\
\text { model predicted }\end{array}$ & Crowley et al. (2008) & $\begin{array}{l}\text { Delaygue and Bard (2009) and } \\
\text { Wang et al. (2005) back }\end{array}$ \\
\hline
\end{tabular}




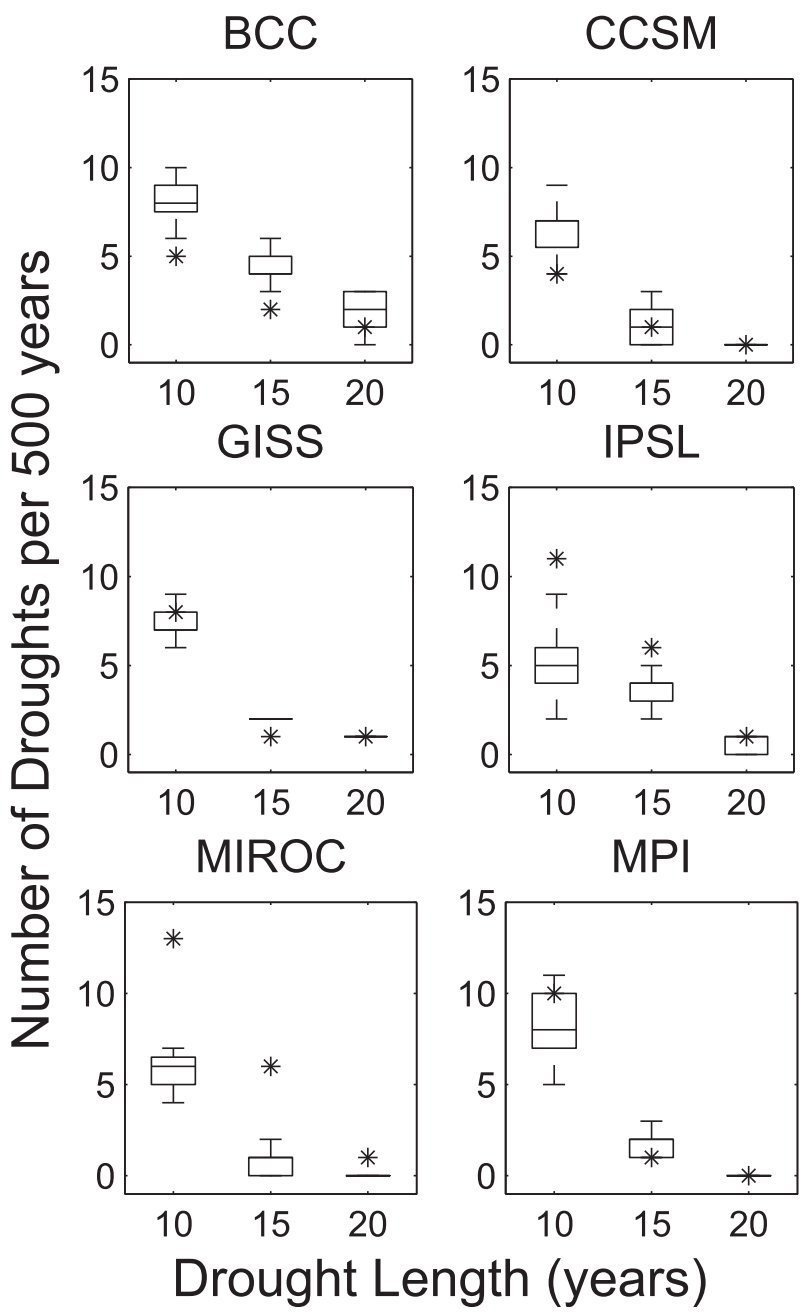

FIG. 5. The numbers of 10-, 15-, and 20-yr droughts (black asterisks) for a 500-yr control simulation are plotted with the range in the number of 10-, 15-, and 20-yr droughts (whiskers are full range; box plot shows mean, 25 th, and 75 th percentile) for a sliding $500-y r$ window of the full 1156-yr period in the forced simulation.

dynamic-mode index is coincident with megadrought years at a percentage greater than $95 \%$ of the artificial indices; this assessment is performed for each individual megadrought (to produce the range in the $95 \%$ significance levels in Fig. 7b) and for all five megadroughts together (Fig. 7a). Additionally, only significant modelindex combinations that follow contemporary understanding of drought dynamics are analyzed (e.g., statistically significant association between megadroughts and the wetting state of a mode are not considered in detail).

Seven model-index combinations satisfied the defined significance requirements: CCSM and IPSL with ENSO; IPSL, MIROC, and MPI with the AMO; and BCC and MIROC with the PDO. These results suggest that multiple dynamical mechanisms can drive megadroughts in the majority of the models. For instance, even in models that have a preferred dynamical driver of megadroughts in Fig. 7a, there can be individual megadroughts that are associated with the wetting phase of that dynamical mode (e.g., two of the MPI megadroughts and the AMO in Fig. 7b). Furthermore, there is little agreement between models on which atmosphere-ocean dynamics are the dominant driver of these features and, in fact, megadroughts driven by internal atmospheric variability cannot be fully discounted for those models that do not exhibit a significant connection to any traditional mode of ocean variability thought to influence hydroclimate conditions over the NASW region (e.g., GISS).

The ability of multiple atmosphere-ocean modes and internal atmospheric variability to drive simulated megadroughts is reaffirmed in Fig. 8, which shows the composite NDJFMA average $200-\mathrm{hPa}$ geopotential height anomaly for the five most severe droughts in each simulation, with the cross-hatched regions showing agreement in sign with the composite anomaly for at least four of the five droughts. As was suggested in Fig. 7, models vary in their geopotential height fields during the simulated megadroughts, indicating that multiple dynamical mechanisms can produce these features. The one relatively consistent feature across the models is a high geopotential height anomaly in the north/central Pacific that would be associated with dry, subsiding air and a northward shift of the storm track away from the NASW. These features are reminiscent of the geopotential height field forced by a La Niña-like state in the tropical Pacific (e.g., Coats et al. 2013b; Seager et al. 2014). The model behavior is similar to what was found in the forced and control ECHO-G simulations analyzed by Coats et al. (2013b), where stochastic atmospheric variability was found to drive persistent drought.

\section{c. Megadroughts in the CCSM simulation}

The tropical Pacific has been hypothesized to play a role in megadroughts because it has been established as the dominant driver of interannual hydroclimate variability in the NASW (Schubert et al. 2004a,b; Seager et al. 2005a, 2008; Herweijer et al. 2006). Given this, a cold tropical Pacific, along with a contribution from a warm tropical Atlantic, has been proposed as a likely cause of the actual North America (NA) megadroughts (Meehl and Hu 2006; Cook et al. 2007; Herweijer et al. 2007; Seager et al. 2007b, 2008; Graham et al. 2007; Oglesby et al. 2011), a hypothesis buoyed by some paleoclimate evidence that the tropical Pacific was cold during the Medieval Climate Anomaly (Cobb et al. 2003; Mann et al. 2009). Despite this, only the CCSM 

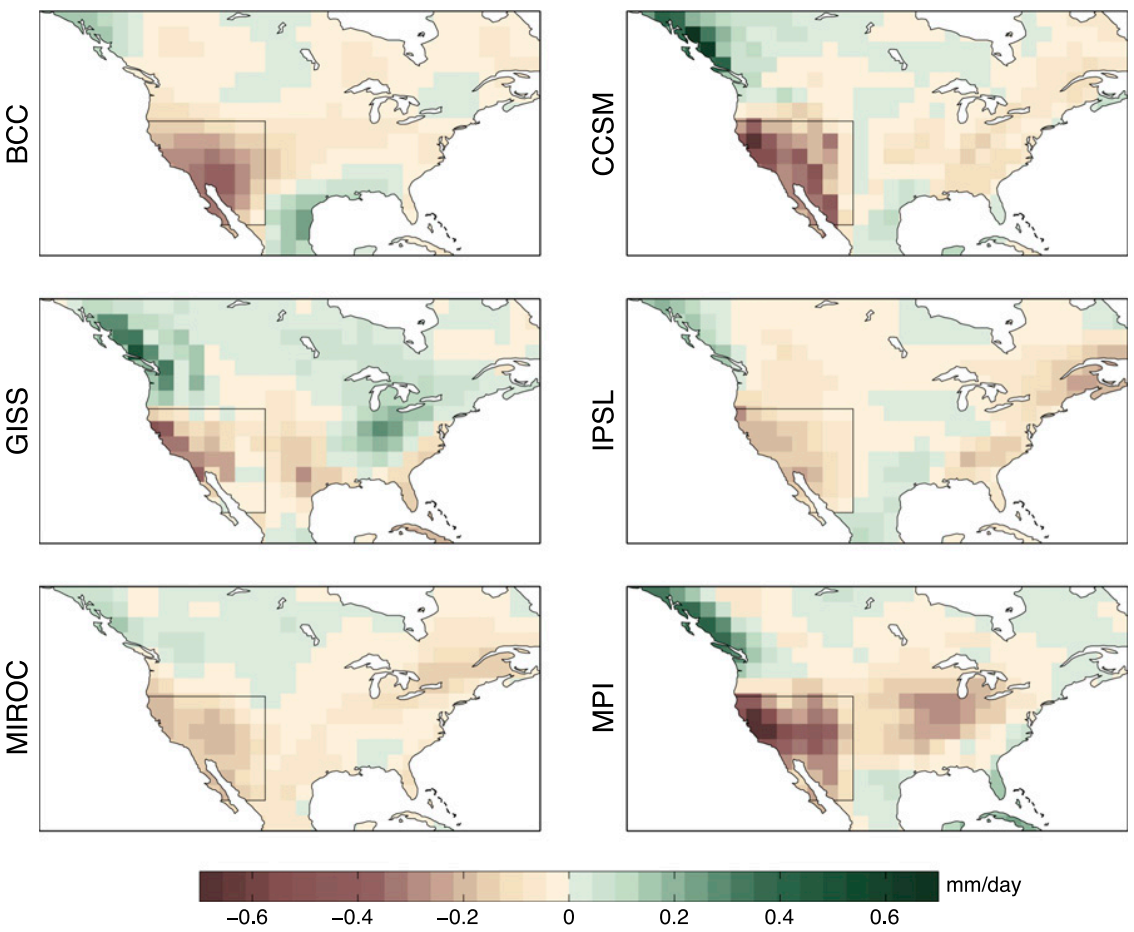

FIG. 6. Time-weighted composite averages of winter (NDJFMA) precipitation anomalies $\left(\mathrm{mm} \mathrm{day}^{-1}\right.$ ) during the five most extreme droughts, as ranked by cumulative drought severity in the control simulations. The full domain is $20^{\circ}-60^{\circ} \mathrm{N}, 150^{\circ}-60^{\circ} \mathrm{W}$. The straight black lines and the western coastline mark the NASW region $\left(25^{\circ}-42.5^{\circ} \mathrm{N}, 125^{\circ}-105^{\circ} \mathrm{W}\right)$.

and IPSL model exhibit a coherent state of the tropical Pacific during the simulated megadroughts. While both models have a tropical Pacific-megadrought connection, the CCSM is anomalous with respect to the control of the tropical Pacific on persistent drought, with all five of the megadroughts coincident with a persistent La Niña-like state (and with $76 \%$ of megadrought years corresponding to a positive TPGR). Next, we examine whether this tropical Pacific-megadrought connection in the CCSM arises from a shift in ENSO variability or the mean state, whether the changes in the tropical $\mathrm{Pa}$ cific are driven by exogenous forcing or internal variability, and why this tropical Pacific-megadrought connection is particularly strong in the CCSM.

\section{1) TropicAl PACIFIC MEAN STATE or ENSO VARIABILITY?}

The top and bottom panels of Fig. 9 show histograms of the percentage of La Niña years (defined as a half standard deviation of the Niño-3.4 index below the mean) and the Niño-3.4 variance in 27-yr windows (chosen to reflect the length of the longest drought in the record). The 27-yr window has been slid every five years through the full length of the CCSM simulation to derive the distributions shown in Fig. 9. The bins with the 27-yr window that corresponds to each of the five most severe droughts in the CCSM simulation are marked with red crosses. The locations of these markers within the statistical distributions demonstrate that megadrought periods in the CCSM simulation are not characterized by a large number of La Niña events or unusual ENSO variance and instead have approximately average Niño-3.4 statistics (mean, variability, and distribution). In contrast, the megadrought periods are consistent with a shift toward a more La Niña-like mean state (as indicated by the anomalously positive TPGR index values in Fig. 7), suggesting that this shift in the mean state is what drives megadroughts in the CCSM.

\section{2) FORCED OR INTERNAL MEAN-STATE CHANGES?}

To assess the dynamics that drive variability in the tropical Pacific in the CCSM on megadrought (10-20 yr) time scales, the EOFs of the 20-yr low-pass filtered tropical Pacific $\left(20^{\circ} \mathrm{S}-20^{\circ} \mathrm{N}, 100^{\circ} \mathrm{E}-70^{\circ} \mathrm{W}\right)$ SST field were computed. The principal components (PCs) were then compared to the TPGR index to determine if a particular mode of variability corresponds to low-frequency variations in the TPGR. The second EOF (Fig. 10) and associated PC explains $90 \%$ of the variance in the TPGR 


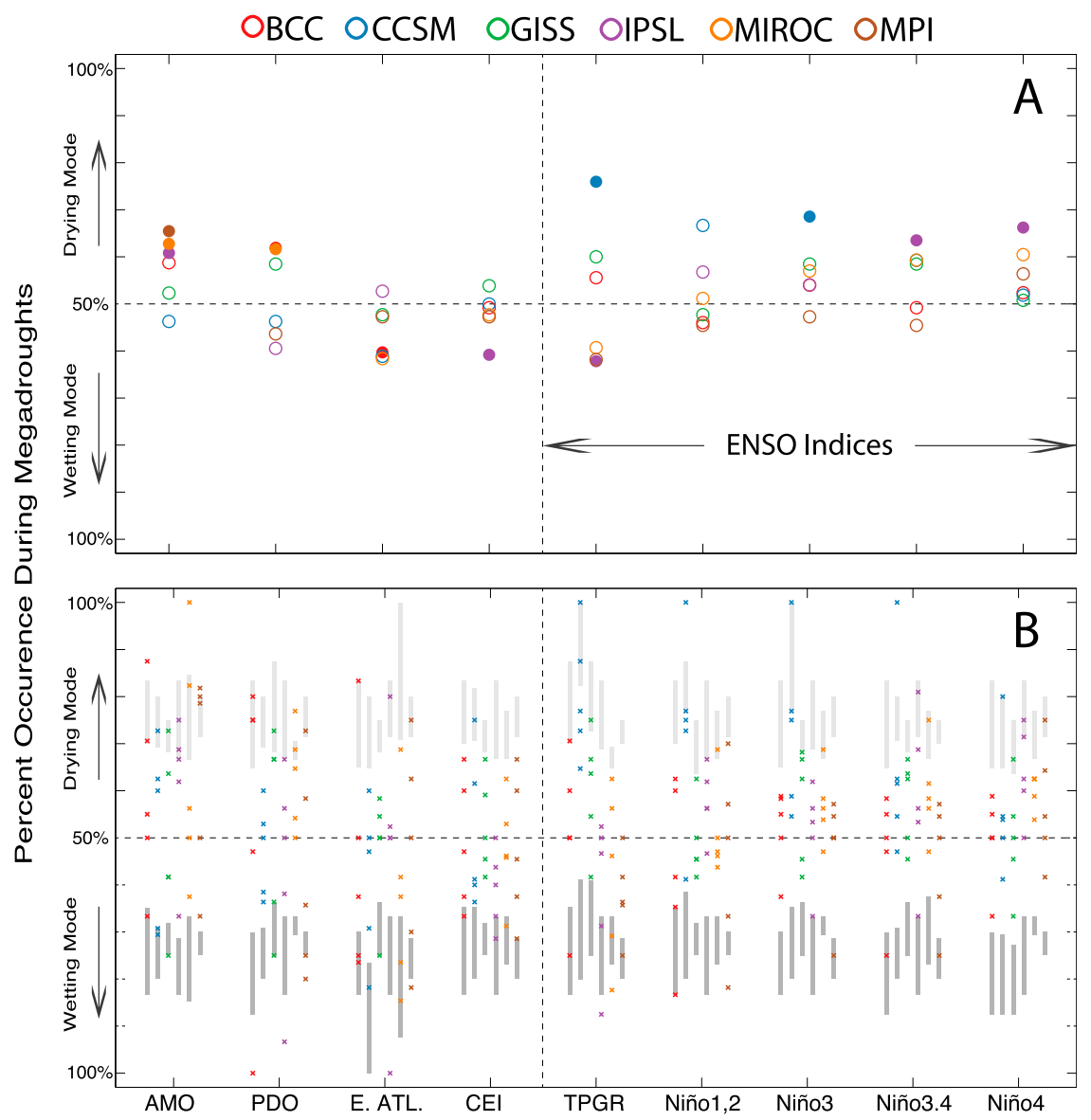

FIG. 7. (a) The percent occurrence of the wetting and drying mode of each dynamical index during the five most severe megadroughts, considered together, with the filled circles being those index-drought combinations that are significant at the $95 \%$ level (using the significance test outlined in section 4b). (b) As in (a), but for each of the individual megadroughts (marked by a cross-five in total). The shaded regions in (b) are the range in $95 \%$ significance level for the individual megadroughts. In both (a) and (b), for index-drought combinations at $100 \%$ drying, every year of the individual megadrought [in (b)] or the five identified megadroughts [in (a)] would have a modal index value (e.g., the TPGR index for ENSO) associated with dry conditions in the NASW (vice versa for wetting).

on these time scales. As noted in Karnauskas et al. (2012), this pattern is consistent with the internal Pacific centennial oscillation (PCO) mode of variability. It is thus the PCO that produces the tropical Pacific meanstate changes in the CCSM that are then driving megadroughts in the NASW.

This suggests that predominantly internal variability of the tropical Pacific Ocean, manifest as changes to the mean state, can drive megadroughts in the CCSM. It is difficult, however, to determine unequivocally that exogenous forcing does not impact mean-state changes in the model, particularly given that forcing can project onto internal modes of climate variability (Palmer 1993). Nevertheless, a comparison of trends in the TPGR on multidecadal time scales in the forced and control simulations indicate that the PCO-driven meanstate changes in the control simulation are as large as any in the forced run (Fig. 11; justification for the use of a 56-yr window to calculate the trend is provided in the following subsection).

\section{3) WHY THE CCSM?}

Why does the CCSM have an extratropical hydroclimate response to mean-state changes in the TPGR, and why do other models not exhibit similar behavior? First, the CCSM, of all the PMIP3 models, yields the largest trends in the TPGR on multidecadal time scales (up to $0.15^{\circ} \mathrm{Cdecade}^{-1}$ for 56 -yr periods; Fig. 11). The $56-\mathrm{yr}$ period was chosen to reflect the length of the National Centers for Environmental Prediction 

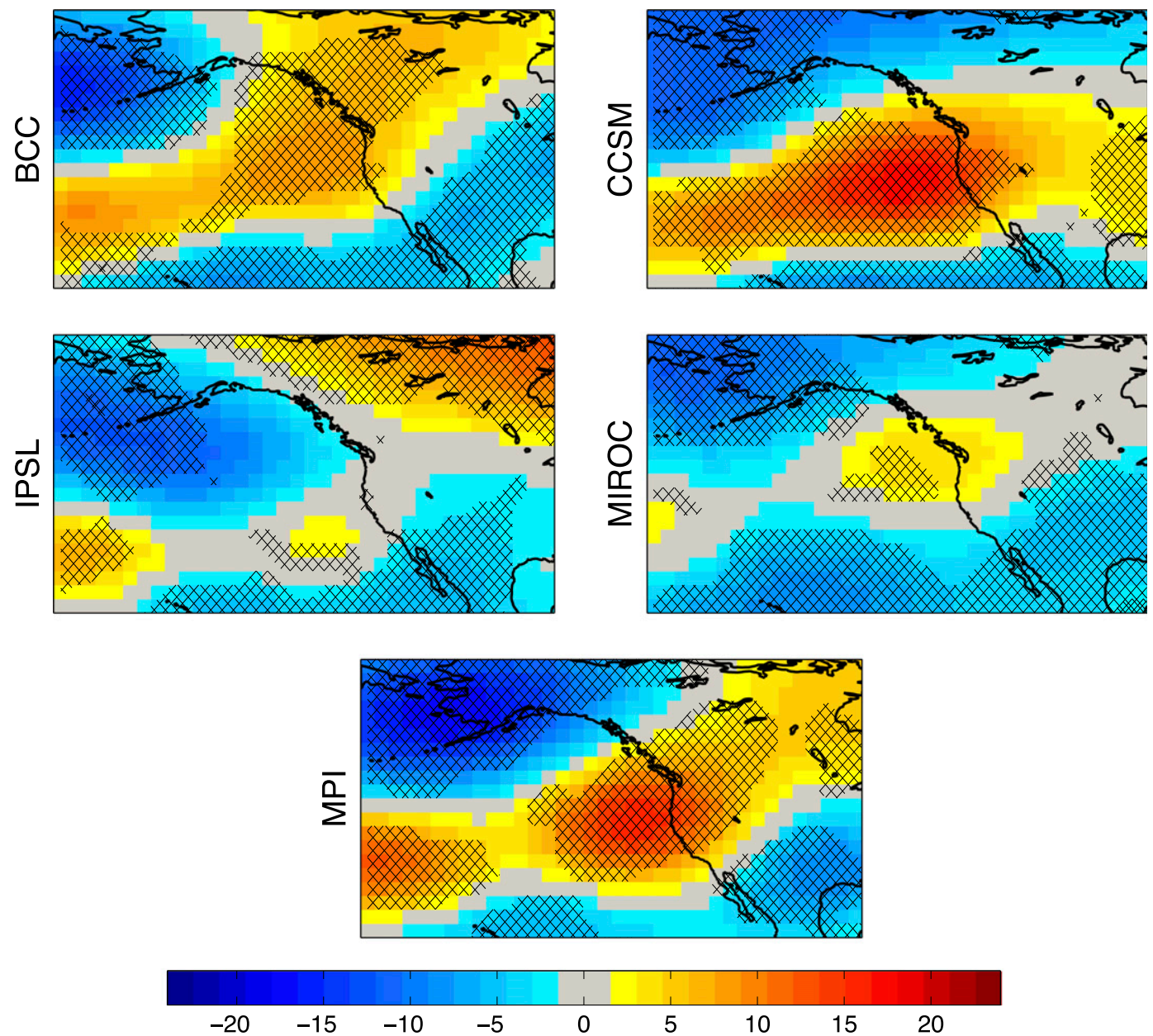

FIG. 8. Composite NDJFMA average geopotential height anomaly for all years identified as occurring during the five most severe droughts in each control simulation. Cross-hatching indicates that the sign of the geopotential height anomaly is in agreement with the composite for at least four out of five identified droughts. The full domain is $20^{\circ}-$ $70^{\circ} \mathrm{N}, 180^{\circ}-90^{\circ} \mathrm{W}$. Note: the GISS simulation does not have geopotential height fields available for the full control simulation and is not included in this figure.

(NCEP)-NCAR reanalysis (Kalnay et al. 1996) and the time period used to assess teleconnection stationarity in Coats et al. (2013a) and in Fig. 12. For reference, a $0.15^{\circ} \mathrm{Cdecade}^{-1}$ trend in the TPGR is 5 times the magnitude of the TPGR trend between 1950 and 2005 in the NCEP-NCAR reanalysis. This result suggests that the CCSM will have the largest multidecadal changes in the mean state of the tropical Pacific Ocean. To maintain consistency with Karnauskas et al. (2012), the same analysis was also completed for 125 -yr trends in the TPGR, and the same relative magnitude of TPGR trends between models was found.

In addition to the strong multidecadal variability in the TPGR, the CCSM exhibits a very realistic NASWENSO teleconnection pattern and strength that is stationary on multidecadal time scales. This is characterized in Fig. 12, which shows winter (DJF) teleconnection stationarity (defined as the Niño-3.4 index correlated with $200-\mathrm{hPa}$ geopotential height), as measured by the centered pattern correlation statistic (CPCS) over NA $\left(20^{\circ}-70^{\circ} \mathrm{N}, 160^{\circ}-50^{\circ} \mathrm{W}\right)$ between the teleconnection patterns estimated from the 1950-2005 period in the NCEPNCAR reanalysis and nonoverlapping 56-yr segments from the forced and control simulations for each of the six models [the full methodology can be found in Coats et al. (2013a)]. Importantly, the consistent representation of the observed interannual connection between NA and the tropical Pacific across the full CCSM simulations is not as robust in the other CMIP5 models, which is to say that the CCSM has the most stationary teleconnection between NA and the tropical Pacific.

Strong tropical Pacific control on NASW hydroclimate occurs over the instrumental period, but if the features of this teleconnection were to change through time, the 

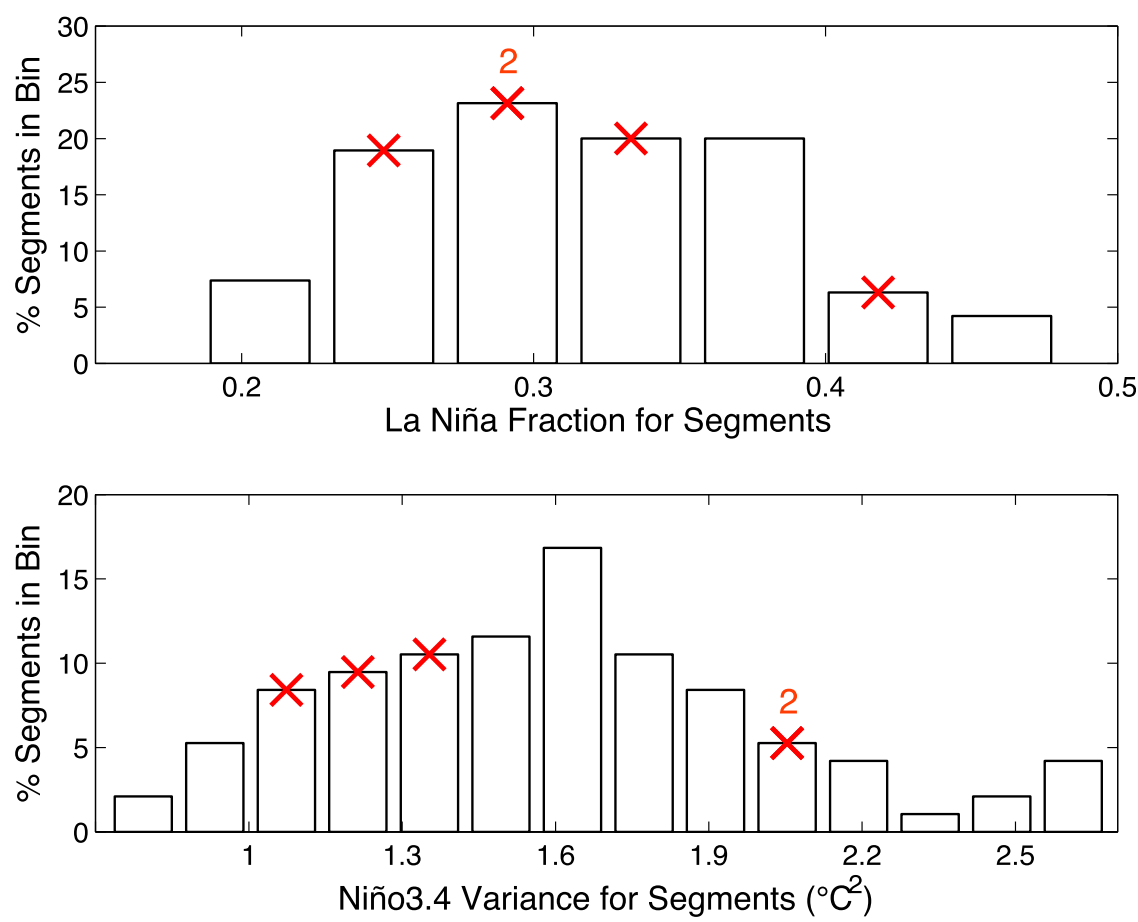

FIG. 9. (top) Histogram of the fraction of La Niña years (defined as a half standard deviation below the mean) in sliding 27-yr segments of the CCSM control simulation. (bottom) Histogram of the Niño-3.4 variance in the same segments. The bins that correspond to the values during the five CCSM megadrought periods are plotted with a red cross (if two fall in the same bin, it is marked as such).

tropical Pacific likely would have varying degrees of control over hydroclimate in the NASW. The fact that the CCSM both faithfully represents the observed teleconnection and maintains the teleconnection features throughout the simulation is critical in this regard and allows changes in the mean state of the tropical Pacific Ocean, which the CCSM simulates with relatively large magnitude, to generate megadroughts. All of the other models exhibit weaker teleconnections that are less realistic and also less stationary, and/or display weaker mean-state changes in the tropical Pacific Ocean. Following the hypothesis of Coats et al. (2013b), such model behavior allows stochastic atmospheric variability and non-ENSO oceanic modes of variability to produce storm track shifts (and associated hydroclimatic changes like NASW drought) that are uninterrupted by tropical Pacific influence.

\section{4) OTHER MODEL BEHAVIOR AND THE CCSM HYPOTHESIS}

As in the CCSM, megadroughts in the IPSL model are significantly connected to the tropical Pacific at the $95 \%$ level. In this case, the significant relationships are between megadroughts and the Niño-3.4 and Niño-4

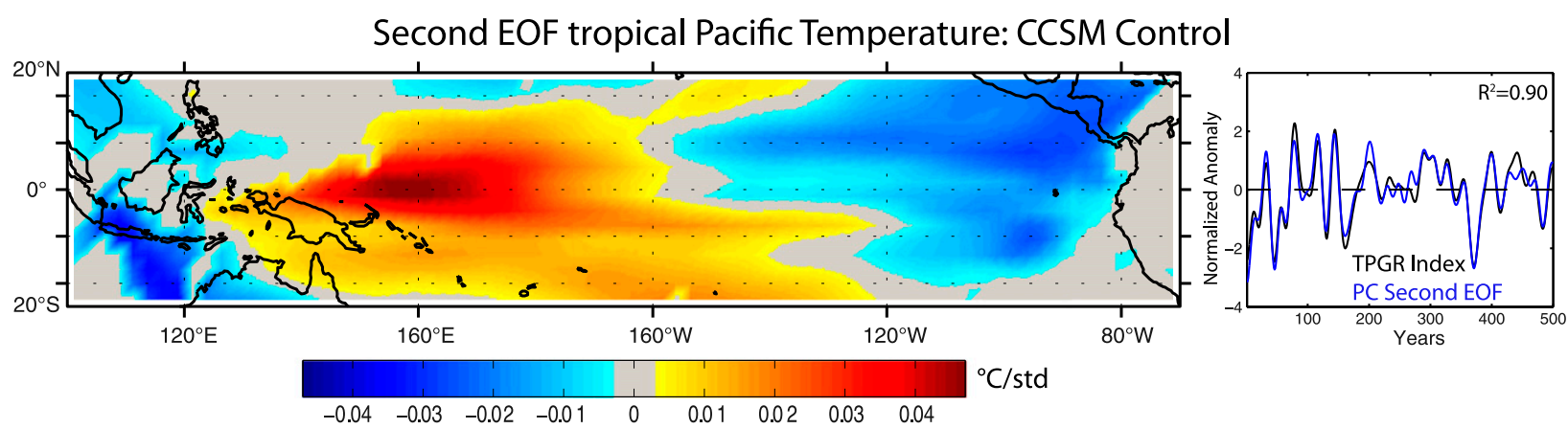

FIG. 10. (left) The pattern of the second EOF in the 20-yr low-pass filtered 500-yr CCSM control simulation. (right) The PC (black) plotted with the 20-yr low-pass filtered TPGR (blue) from that simulation. The $R^{2}$ between these time series is listed at top right in (right). 


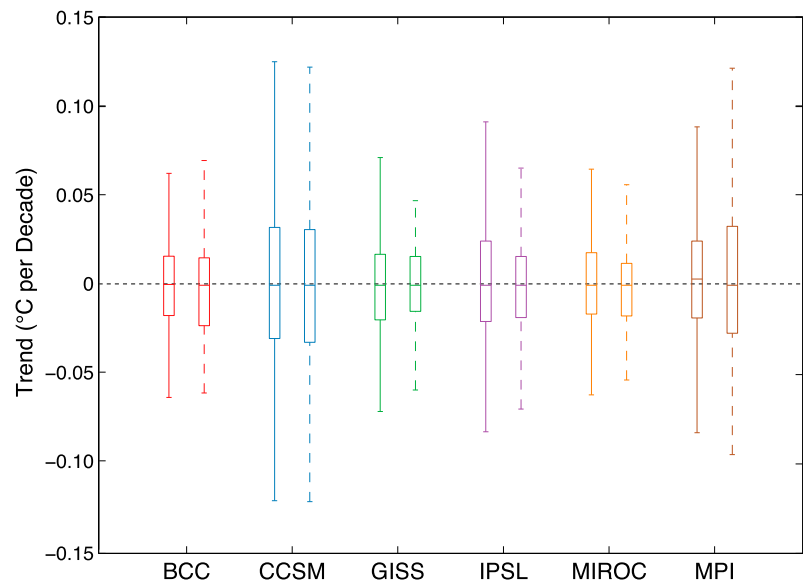

FIG. 11. Range of trends in the TPGR $\left({ }^{\circ} \mathrm{Cdecade}^{-1}\right)$ for 56 -yr sliding windows in each forced (solid whiskers) and control (dashed whiskers) simulation. A La Niña-like trend is positive.

indices, but importantly, these connections are weaker than between the CCSM and the TPGR (with $65 \%$ and $67 \%$ of megadrought years corresponding to the drying mode of these indices, respectively; Fig. 7). Interestingly, the IPSL model also shows a significant connection between megadroughts and a negative or El Niño-like state in the TPGR. This is indicative of what was suggested in section 2c, that some ENSO indices do not adequately capture ENSO variability in some models.

The behavior of IPSL - which has a significant connection between megadroughts and the tropical Pacific, but one that is weaker than in the CCSM-and the other models that do not exhibit this connection can be better understood in the context of the CCSM behavior outlined in the previous section. If models have a realistic and stationary teleconnection, with large multidecadal variability in the tropical Pacific Ocean, as in the CCSM, then the simulated megadroughts should be driven consistently by the tropical Pacific boundary conditions. The IPSL model does, in fact, exhibit a strong and stationary teleconnection between North America and the tropical Pacific (Fig. 11). Furthermore, it has moderate variability in the tropical Pacific Ocean, exceeded only by the MPI model and the CCSM. In the context of the above-outlined hypothesis, if this variability were larger, the connection between the tropical Pacific and megadroughts would be stronger, as in the CCSM. Nevertheless, The IPSL model has the most CCSM-like tropical Pacific variability and teleconnection behavior, and, of the other five models analyzed herein, would be expected to have megadroughts that are most strongly connected to the tropical Pacific boundary conditions.

The other models exhibit fewer of the characteristics hypothesized to be necessary for simulating megadroughts that are consistently forced by the

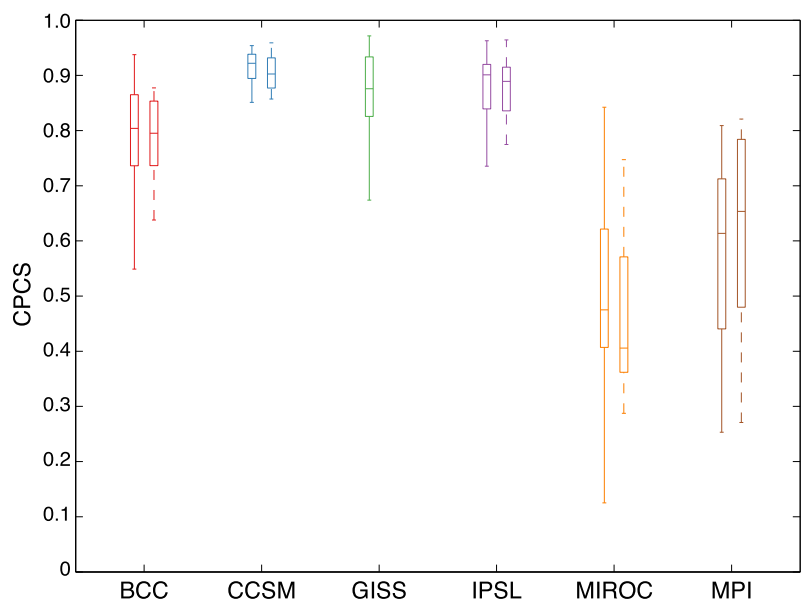

FIG. 12. Winter (DJF) teleconnection (defined as the Niño-3.4 index correlated with 500 -hPa geopotential height) stationarity, as measured by the CPCS over NA $\left(20^{\circ}-70^{\circ} \mathrm{N}, 160^{\circ}-50^{\circ} \mathrm{W}\right)$ between the teleconnection patterns estimated from the NCEP-NCAR reanalysis and nonoverlapping 56-yr segments from the forced (solid whiskers) and control (dashed whiskers) simulations. Box plots indicate the 75th and 25th percentile of the CPCS across the segments in the respective model runs with the median as the bolded line and the whiskers showing the full data, excluding outliers. Full methodology can be found in Coats et al. (2013a). (Note: the GISS simulation does not have geopotential height fields available for the full control simulation and is not included in this figure).

tropical Pacific boundary conditions. The BCC and GISS models have a moderately realistic and stationary teleconnection but weak variability in the tropical $\mathrm{Pa}$ cific on multidecadal time scales. The MPI model has large variability in the tropical Pacific on multidecadal time scales but a highly nonstationary teleconnection. The MIROC model has both weak variability in the tropical Pacific and a highly nonstationary and likewise unrealistic teleconnection.

\section{Discussion and conclusions}

Models from the CMIP5/PMIP3 generation are capable of simulating megadroughts in the NASW that are similar in duration and magnitude to those observed in the paleoclimate record. The droughts are not, however, temporally synchronous with those in the proxy record. Furthermore, there is very little overlap between the drought features in the LM runs, despite the use of similar forcing series to drive these simulations. This suggests that model-simulated megadroughts can result from internal variability of the modeled climate system, rather than as a response to changes in exogenous forcings, or that models exhibit compensation between feedback mechanisms that masks a forced hydroclimate response. 
While stochastic atmospheric variability is able to drive persistent drought in AOGCMs (Coats et al. 2013b), it is not a robust feature. In particular, models with strong and stationary teleconnections (e.g., CCSM) and large multidecadal variability in the tropical Pacific, simulate megadroughts driven by internal variability of the tropical Pacific mean state. If models with these characteristics are, in fact, more representative of the actual climate system, these results will have important consequences for the cause and predictability of regional extratropical hydroclimate on decadal-to-multidecadal time scales. In this case, multidecadal hydroclimate variability and megadroughts would be lower-frequency analogs of the more familiar annual events, both driven by the tropical Pacific Ocean. If indeed true, this characteristic might provide some predictability based on long-time-scale characteristics of the state of the tropical Pacific Ocean, although operational prediction has yet to exceed the seasonal time scale (e.g., Barnston et al. 2012; Zhu et al. 2012).

Low-frequency hydroclimate variability driven by the atmosphere and SST variability outside the tropical Pacific are nevertheless common model features. Given that these same models are used to produce future projections, it is critical to better understand this model behavior in the context of the actual climate system. Efforts involving the analysis of specific models and ensemble behavior from a dynamical perspective, as performed herein, complement approaches that employ a statistical rescaling of model output using information about real-world hydroclimate persistence from the observed and paleo-proxy record to assess the risk of future hydroclimate change (e.g., Ault et al. 2012, 2013). A model can both succeed and fail at reproducing observed persistence characteristics for a variety of dynamical reasons; understanding what drives the simulated hydroclimate dynamics on these time scales will help provide reliable information on the risk of future drought in the NASW. Along these lines, a comprehensive global multimodel drought attribution study using available proxy data would be useful to determine the varying mechanisms of drought generation in the CMIP5 models and determine which models most faithfully represent reality and, therefore, may better represent future hydroclimate responses to increasing greenhouse gas concentrations. To do this with certainty will require, in particular, longer records of proxyestimated tropical Pacific SSTs (e.g., Emile-Geay et al. 2013) and additional regional records of hydroclimate variability over the last millennium (e.g., Cook et al. 2010; for monsoon Asia). Combining such paleoclimate products with continued model work promises to both improve our understanding of past hydroclimate variability and the way in which we represent important climatic processes in climate models, the latter of which is essential for accurately constraining projected hydroclimate risks in the twenty-first century.

Acknowledgments. This work was supported by NOAA awards NA10OAR4310137 [Global Decadal Hydroclimate Variability and Change $(\mathrm{GloDecH})]$ and NA11OAR4310166 and NSF award ATM-0902716. Additional support for B.I. Cook was provided by National Aeronautics and Space Administration Modeling Analysis and Prediction Program WBS 281945.02.04.02.74 ("Cool and Warm Season Moisture Reconstruction and Modeling over North America"). We acknowledge the World Climate Research Programme's Working Group on Coupled Modelling, which is responsible for CMIP, and we thank the climate modeling groups (listed in Table 1) for producing and making available their model output. For CMIP, the U.S. Department of Energy's Program for Climate Model Diagnosis and Intercomparison provides coordinating support and led development of software infrastructure in partnership with the Global Organization for Earth System Science Portal. We thank three anonymous reviewers for comments that greatly improved the quality of this manuscript. We further thank Haibo Liu and Naomi Henderson for their considerable computational support.

\section{REFERENCES}

Ault, T. R., J. E. Cole, and S. St. George, 2012: The amplitude of decadal to multidecadal variability in precipitation simulated by state-of-the-art climate models. Geophys. Res. Lett., 39, L21705, doi:10.1029/2012GL053424.

,,-- J. T. Overpeck, G. T. Pederson, S. St. George, B. OttoBliesner, C. A. Woodhouse, and C. Deser, 2013: The continuum of hydroclimate variability in western North America during the last millennium. J. Climate, 26, 5863-5878, doi:10.1175/JCLI-D-11-00732.1.

Barnston, A. G., M. K. Tippett, M. L. L'Heureux, S. Li, and D. G. DeWitt, 2012: Skill of real-time seasonal ENSO model predictions during 2002-11: Is our capability increasing? Bull. Amer. Meteor. Soc., 93, 631-651, doi:10.1175/BAMS-D-11-00111.1.

Becker, A., P. Finger, A. Meyer-Christoffer, B. Rudolf, K. Schamm, U. Schneider, and M. Ziese, 2013: A description of the global land-surface precipitation data products of the Global Precipitation Climatology Centre with sample applications including centennial (trend) analysis from 1901-present. Earth Syst. Sci. Data, 5, 71-99, doi:10.5194/essd-5-71-2013.

Bothe, O., J. H. Jungclaus, and D. Zanchettin, 2013: Consistency of the multi-model CMIP5/PMIP3-past1000 ensemble. Climate Past, 9, 2471-2487, doi:10.5194/cp-9-2471-2013.

Clement, A. C., R. Seager, M. A. Cane, and S. E. Zebiak, 1996: An ocean dynamical thermostat. J. Climate, 9, 2190-2196, doi:10.1175/1520-0442(1996)009<2190:AODT>2.0.CO;2.

Coats, S., J. E. Smerdon, B. I. Cook, and R. Seager, 2013a: Stationarity of the tropical Pacific teleconnection to North America in CMIP5/PMIP3 model simulations. Geophys. Res. Lett., 40, 4927-4932, doi:10.1002/grl.50938. 
R. Seager, B. I. Cook, and J. F. González-Rouco, 2013b: Megadroughts in southwestern North America in ECHO-G millennial simulations and their comparison to proxy drought reconstructions. J. Climate, 26, 7635-7649, doi:10.1175/JCLI-D-12-00603.1.

Cobb, K. M., C. D. Charles, H. Cheng, and R. L. Edwards, 2003: El Niño/Southern Oscillation and tropical Pacific climate during the last millennium. Nature, 424, 271-276, doi:10.1038/nature01779.

Cook, B. I., J. E. Smerdon, R. Seager, and S. Coats, 2014: Global warming and 21st century drying. Climate Dyn., 43, 2607-2627, doi:10.1007/s00382-014-2075-y.

Cook, E. R., R. Seager, M. A. Cane, and D. W. Stahle, 2007: North American drought: Reconstructions, causes, and consequences. Earth-Sci. Rev., 81, 93-134, doi:10.1016/j.earscirev.2006.12.002.

—, K. J. Anchukaitis, B. M. Buckley, R. D. D’Arrigo, G. C. Jacoby, and W. E. Wright, 2010: Asian monsoon failure and megadrought during the last millennium. Science, 328, 486489, doi:10.1126/science.1185188.

Crowley, T., G. Zielinski, B. Vinther, R. Udisti, K. Kreutz, J. Cole-Dai, and E. Castellano, 2008: Volcanism and the Little Ice Age. PAGES News, Vol. 16, PAGES International Project Office, Bern, Switzerland, 22-23.

Dai, A., 2013: Increasing drought under global warming in observations and models. Nat. Climate Change, 3, 52-58, doi:10.1038/nclimate1633.

Delaygue, G and E. Bard, 2009: Solar forcing based on Be-10 in Antarctica ice over the past millennium and beyond. Extended Abstracts, EGU General Assembly 2009, Vienna, Austria, European Geosciences Union, EGU2009-6943.

DiNezio, P. N., A. C. Clement, G. A. Vecchi, B. J. Soden, B. P. Kirtman, and S.-K. Lee, 2009: Climate response of the equatorial Pacific to global warming. J. Climate, 22, 4873-4892, doi:10.1175/2009JCLI2982.1.

Emile-Geay, J., K. M. Cobb, M. E. Mann, and A. T. Wittenberg, 2013: Estimating central equatorial Pacific SST variability over the past millennium. Part II: Reconstructions and implications. J. Climate, 26, 2329-2352, doi:10.1175/JCLI-D-11-00511.1.

Enfield, D. B., A. M. Mestas-Nuñez, and P. J. Trimble, 2001: The Atlantic Multidecadal Oscillation and its relation to rainfall and river flows in the continental U.S. Geophys. Res. Lett., 28, 2077-2080, doi:10.1029/2000GL012745.

Feng, S., R. J. Oglesby, C. M. Rowe, D. B. Loope, and Q. Hu, 2008: Atlantic and Pacific SST influences on medieval drought in North America simulated by the Community Atmospheric Model. J. Geophys. Res., 113, D11101, doi:10.1029/2007JD009347.

Gao, C., A. Robock, and C. Ammann, 2008: Volcanic forcing of climate over the past 1500 years: An improved ice core-based index for climate models. J. Geophys. Res., 113, D2311, doi:10.1029/2008JD010239.

Gochis, D., J. Schemm, W. Shi, L. Long, W. Higgins, and A. Douglas, 2009: A forum for evaluating forecasts of the North American monsoon. Eos, Trans. Amer. Geophys. Union, 90, 249-251, doi:10.1029/2009EO290002.

Goddard, L., and N. E. Graham, 1999: Importance of the Indian Ocean for simulating rainfall anomalies over eastern and southern Africa. J. Geophys. Res., 104, 19099-19116, doi:10.1029/1999JD900326.

Graham, N. E., and Coauthors, 2007: Tropical Pacific-Mid-latitude teleconnections in medieval times. Climatic Change, 83, 241285, doi:10.1007/s10584-007-9239-2.

Griffin, D., and Coauthors, 2013: North American monsoon precipitation reconstructed from tree-ring latewood. Geophys. Res. Lett., 40, 954-958, doi:10.1002/grl.50184.
Held, I. M., and B. J. Soden, 2006: Robust responses of the hydrological cycle to global warming. J. Climate, 19, 5686-5699, doi:10.1175/JCLI3990.1.

Herweijer, C., R. Seager, and E. R. Cook, 2006: North American droughts of the mid to late nineteenth century: A history, simulation and implication for Mediaeval drought. Holocene, 16, 159-171, doi:10.1191/0959683606hl917rp.

— _ — - — , and J. Emile-Geay, 2007: North American droughts of the last millennium from a gridded network of tree-ring data. J. Climate, 20, 1353-1376, doi:10.1175/ JCLI4042.1.

Hoerling, M., and A. Kumar, 2003: The perfect ocean for drought. Science, 299, 691-694, doi:10.1126/science.1079053.

Kalnay, E., and Coauthors, 1996: The NCEP/NCAR 40-Year Reanalysis Project. Bull. Amer. Meteor. Soc., 77, 437-471, doi:10.1175/1520-0477(1996)077<0437:TNYRP>2.0.CO;2.

Karnauskas, K. B., R. Seager, A. Kaplan, Y. Kushnir, and M. A. Cane, 2009: Observed strengthening of the zonal sea surface temperature gradient across the equatorial Pacific Ocean. J. Climate, 22, 4316-4321, doi:10.1175/2009JCLI2936.1.

_ J. E. Smerdon, R. Seager, and J. F. González-Rouco, 2012: A Pacific centennial oscillation predicted by coupled GCMs. J. Climate, 25, 5943-5961, doi:10.1175/JCLI-D-11-00421.1.

Kushnir, Y., R. Seager, M. Ting, N. Naik, and J. Nakamura, 2010: Mechanisms of tropical Atlantic SST influence on North American precipitation variability. J. Climate, 23, 5610-5628, doi:10.1175/2010JCLI3172.1.

Langford, S., S. Stevenson, and D. Noone, 2014: Analysis of lowfrequency precipitation variability in CMIP5 historical simulations for southwestern North America. J. Climate, 27, 27352756, doi:10.1175/JCLI-D-13-00317.1.

Mann, M. E., and Coauthors, 2009: Global signatures and dynamical origins of the Little Ice Age and Medieval Climate Anomaly. Science, 27, 1256-1260, doi:10.1126/science.1177303.

McCabe, G. J., M. A. Palecki, and J. L. Betancourt, 2004: Pacific and Atlantic Ocean influences on multidecadal drought frequency in the United States. Proc. Natl. Acad. Sci. USA, 101, 4136-4141, doi:10.1073/pnas.0306738101.

Meehl, G. A., and A. Hu, 2006: Megadroughts in the Indian monsoon region and southwest North America and a mechanism for associated multidecadal Pacific sea surface temperature anomalies. J. Climate, 19, 1605-1623, doi:10.1175/JCLI3675.1.

Milly, P. C. D., and K. A. Dunne, 2011: On the hydrologic adjustment of climate-model projections: The potential pitfall of potential evapotranspiration. Earth Interact., 15, 1-14, doi:10.1175/ 2010EI363.1.

Oglesby, J. R., S. Feng, Q. Hu, and C. Rowe, 2011: Medieval drought in North America: The role of the Atlantic multidecadal oscillation. PAGES News, Vol. 19, PAGES International Project Office, Bern, Switzerland, 18-19.

Pachauri, R. K., and A. Reisinger, Eds., 2007: Climate Change 2007: Synthesis Report. Cambridge University Press, 104 pp.

Palmer, T. N., 1993: Extended-range atmospheric prediction and the Lorenz model. Bull. Amer. Meteor. Soc., 74, 49-65, doi:10.1175/1520-0477(1993)074<0049:ERAPAT>2.0.CO;2.

Sarachik, E. S., and M. A. Cane, 2010: The El Niño-Southern Oscillation Phenomenon. Cambridge University Press, 384 pp.

Schmidt, G. A., and Coauthors, 2011: Climate forcing reconstructions for use in PMIP simulations of the last millennium (v1.0). Geosci. Model Dev., 4, 33-45, doi:10.5194/gmd-4-33-2011.

_ constrain future projections in CMIP5. Climate Past, 9, 775835, doi:10.5194/cpd-9-775-2013. 
Schreiber, T., and A. Schmitz, 2000: Surrogate time series. Physica D, 142, 346-382, doi:10.1016/S0167-2789(00)00043-9.

Schubert, S. D., M. J. Suarez, P. J. Pegion, R. D. Koster, and J. Bacmeister, 2004a: Causes of long-term drought in the U.S. Great Plains. J. Climate, 17, 485-503, doi:10.1175/ 1520-0442(2004)017<0485:COLDIT >2.0.CO;2. and $2004 \mathrm{~b}$ : On the cause of the 1930s Dust Bowl. Science, 303, 1855-1859, doi:10.1126/science.1095048. Seager, R., and G. Vecchi, 2010: Greenhouse warming and the 21st century hydroclimate of southwestern North America. Proc. Natl. Acad. Sci. USA, 107, 256-262, doi:10.1073/ pnas.0910856107.

, N. Harnik, W. A. Robinson, Y. Kushnir, M. Ting, H.-P. Huang, and J. Velez, 2005a: Mechanisms of ENSO-forcing of hemispherically symmetric precipitation variability. Quart. J. Roy. Meteor. Soc., 131, 1501-1527, doi:10.1256/qj.04.96.

, Y. Kushnir, C. Herweijer, N. Naik, and J. Velez, 2005b: Modeling of tropical forcing of persistent droughts and pluvials over western North America: 1856-2000. J. Climate, 18, 4065-4088, doi:10.1175/JCLI3522.1.

_ , and Coauthors, 2007a: Model projections of an imminent transition to a more arid climate in southwestern North America. Science, 316, 1181-1184, doi:10.1126/science.1139601.

—, N. Graham, C. Herweijer, A. L. Gordon, Y. Kushnir, and E. Cook, 2007b: Blueprints for Medieval hydroclimate. Quat. Sci. Rev., 26, 2322-2336, doi:10.1016/j.quascirev.2007.04.020.

_ , R. Burgman, Y. Kushnir, A. Clement, E. Cook, N. Naik, and J. Miller, 2008: Tropical Pacific forcing of North American medieval megadroughts: Testing the concept with an atmosphere model forced by coral-reconstructed SSTs. J. Climate, 21, 6175-6190, doi:10.1175/2008JCLI2170.1.

, N. Naik, and G. A. Vecchi, 2010: Thermodynamic and dynamic mechanisms for large-scale changes in the hydrological cycle in response to global warming. J. Climate, 23, 4651-4668, doi:10.1175/2010JCLI3655.1.

_- M. Ting, C. Li, N. Naik, B. Cook, J. Nakamura, and H. Liu, 2013: Projections of declining surface-water availability for the southwestern United States. Nat. Climate Change, 3, 482-486, doi:10.1038/nclimate1787.

— L. L. Goddard, J. Nakamura, N. Henderson, and D.-E. Lee, 2014: Dynamical causes of the 2010/11 Texas-northern Mexico drought. J. Hydrometeor., 15, 39-68, doi:10.1175/ JHM-D-13-024.1.

Sen Gupta, A., N. C. Jourdain, J. N. Brown, and D. Monselesan, 2013: Climate drift in the CMIP5 models. J. Climate, 26, 85978615, doi:10.1175/JCLI-D-12-00521.1.

Sheffield, J., E. F. Wood, and M. L. Roderick, 2012: Little change in global drought over the past 60 years. Nature, 491, 435-438, doi:10.1038/nature11575.

— , and Coauthors, 2013: North American climate in CMIP5 experiments. Part I: Evaluation of historical simulations of continental and regional climatology. J. Climate, 26, 92099245, doi:10.1175/JCLI-D-12-00592.1.

Stevenson, S., B. Fox-Kemper, M. Jochum, R. Neale, C. Deser, and G. Meehl, 2012: Will there be a significant change to El Niño in the twenty-first century? J. Climate, 25, 2129-2145, doi:10.1175/JCLI-D-11-00252.1.
St. George, S., D. M. Meko, and E. R. Cook, 2010: The seasonality of precipitation signals encoded within the North American Drought Atlas. Holocene, 20, 983-988, doi:10.1177/0959683610365937.

Stocker, T. F., and Coauthors, 2013: Climate Change 2013: The Physical Science Basis. Cambridge University Press, 1535 pp. [Available online at http://www.ipcc.ch/pdf/assessmentreport/ar5/wg1/WG1AR5_ALL_FINAL.pdf.]

Sueyoshi, T., and Coauthors, 2013: Set-up of the PMIP3 paleoclimate experiments conducted using an Earth system model, MIROC-ESM. Geosci. Model Dev., 6, 819-836, doi:10.5194/ gmd-6-819-2013.

Sun, S., and G. Wang, 2014: Climate variability attributable to terrestrial and oceanic forcing in the NCAR CAM3-CLM3 models. Climate Dyn., 42, 2067-2078, doi:10.1007/s00382-013-1913-7.

Sutton, R. T., and D. L. R. Hodson, 2005: Atlantic Ocean forcing of North American and European summer climate. Science, 309, 115-118, doi:10.1126/science.1109496.

Taylor, K. E., R. J. Stouffer, and G. A. Meehl, 2012: An overview of CMIP5 and the experiment design. Bull. Amer. Meteor. Soc., 93, 485-498, doi:10.1175/BAMS-D-11-00094.1.

Thornthwaite, C. W., 1948: An approach toward a rational classification of climate. Geogr. Rev., 38, 55-94, doi:10.2307/210739.

Ting, M., Y. Kushnir, R. Seager, and C. Li, 2011: Robust features of Atlantic multi-decadal variability and its climate impacts. Geophys. Res. Lett., 38, L17705, doi:10.1029/2011GL048712.

van der Schrier, G., P. D. Jones, and K. R. Briffa, 2011: The sensitivity of the PDSI to the Thornthwaite and Penman-Monteith parameterizations for potential evapotranspiration. J. Geophys. Res., 116, D03106, doi:10.1029/2010JD015001.

Vecchi, G. A., B. J. Soden, A. T. Wittenberg, I. M. Held, A. Leetmaa, and M. J. Harrison, 2006: Weakening of tropical Pacific atmospheric circulation due to anthropogenic forcing. Nature, 441, 73-76, doi:10.1038/nature04744.

_ A. Alement, and B. J. Soden, 2008: Examining the tropical Pacific's response to global warming. Eos, Trans. Amer. Geophys. Union, 89, 81-83, doi:10.1029/2008EO090002.

Vicente-Serrano, S. M., S. Beguería, and J. I. López-Moreno, 2010: A multiscalar drought index sensitive to global warming: The standardized evapotranspiration index. J. Climate, 23, 16961718, doi:10.1175/2009JCLI2909.1.

Vieira, L.E.A., and S. K. Solanki, 2010: Evolution of the solar magnetic flux on time scales of years to millenia. Astron. Astrophys., 509, A100, doi:10.1051/0004-6361/200913276.

Wang, Y.-M., J. L. Lean, and N. R. Sheeley Jr., 2005: Modeling the sun's magnetic field and irradiance since 1713. Astrophys. J., 625, 522-538, doi:10.1086/429689.

Wild, M., D. Folini, C. Schär, N. Loeb, E. G. Dutton, and G. König-Langlor, 2013: The global energy balance from a surface perspective. Climate Dyn., 40, 3107-3134, doi:10.1007/ s00382-012-1569-8.

Zhang, Y., J. M. Wallace, and D. S. Battisti, 1997: ENSO-like interdecadal variability: 1990-93. J. Climate, 10, 1004-1020, doi:10.1175/1520-0442(1997)010<1004:ELIV > 2.0.CO;2.

Zhu, J., B. Huang, L. Marx, J. L. Kinter III, M. A. Balmaseda, R.-H. Zhang, and Z.-Z. Hu, 2012: Ensemble ENSO hindcasts initialized from multiple ocean analyses. Geophys. Res. Lett., 39, L09602, doi:10.1029/2012GL051503. 